Running head: REFLECTION AND DILEMMA JUDGMENT

Accepted for publication in Cognition. Please cite final, copyedited version when available.

DOI: $\underline{\text { 10.1016/j.cognition.2019.06.007 }}$

Not All Who Ponder Count Costs: Arithmetic Reflection Predicts Utilitarian Tendencies, but Logical Reflection Predicts both Deontological and Utilitarian Tendencies

$\underline{\text { Nick Byrd }} *$ \& Paul Conway

Florida State University, USA

*Corresponding author:

Nick Byrd, Philosophy Department

641 University Way

151 Dodd Hall

Tallahassee, FL 32306-1500

United States

nick.a.byrd@gmail.com

byrdnick.com 


\begin{abstract}
Conventional sacrificial moral dilemmas propose directly causing some harm to prevent greater harm. Theory suggests that accepting such actions (consistent with utilitarian philosophy) involves more reflective reasoning than rejecting such actions (consistent with deontological philosophy). However, past findings do not always replicate, confound different kinds of reflection, and employ conventional sacrificial dilemmas that treat utilitarian and deontological considerations as opposite. In two studies, we examined whether past findings would replicate when employing process dissociation to assess deontological and utilitarian inclinations independently. Findings suggested two categorically different impacts of reflection: measures of arithmetic reflection, such as the Cognitive Reflection Test, predicted only utilitarian, not deontological, response tendencies. However, measures of logical reflection, such as performance on logical syllogisms, positively predicted both utilitarian and deontological tendencies. These studies replicate some findings, clarify others, and reveal opportunity for additional nuance in dual process theorists' claims about the link between reflection and dilemma judgments.
\end{abstract}

Keywords: moral dilemmas; process dissociation; dual-process theory; cognitive reflection test; belief bias; moral psychology 


\section{Not All Who Ponder Count Costs: Arithmetic Reflection Predicts Utilitarian Inclinations, but Logical Reflection Predicts both Deontological and Utilitarian Inclinations}

Imagine a nurse working at your hospital became infected with a rare contagious virus. She is only a viral carrier, so she will recover, but the virus will spread, killing many others. The only way to stop the virus is to give her antiviral medication - but she is allergic to this medication and will die from its side effects. Is it appropriate to give her the medication to prevent the deadly virus from spreading, even though this will kill her? Imagine you took time to ponder your decision. According to the popular dual process theory, reflecting on such dilemmas involves calculating the difference between lives saved versus lives lost, thereby increasing the likelihood that reflective decision-makers accept performing harmful actions with net benefits (e.g., Greene et al., 2004). Yet, some theorists have cast doubt on this view of reflection (e.g., Baron, Scott, Fincher, \& Metz, 2015), and other work suggests that reflection can sometimes increase harm-rejection responses (e.g., McPhetres, Conway, Hughes, \& Zuckerman, 2018). One possibility for resolving these inconsistencies is to posit that different types of reflection have different impacts on dilemma decision-making, and that past work has remained largely insensitive to these differences. If so, then the impact of reflection on dilemma decisions may be more complex and multifaceted than previously believed.

Past work on this issue has typically examined how responses on measures like the Cognitive Reflection Test (CRT, Frederick 2005) predict sacrificial dilemma judgments. The CRT assesses cognitive reasoning via performance on math problems that lure test-takers toward intuitive but incorrect answers. People who score higher on the CRT are frequently more willing to cause some harm that mitigates overall harm (e.g., Baron et al., 2015; Byrd, 2019; Royzman, 
Landy, \& Leeman, 2014). ${ }^{1}$ Such findings have been described as support for the dual process claim that utilitarian judgments require overcoming unreflective harm aversion responses with mathematical comparisons of each outcome of the dilemma (e.g., Paxton, Unger, \& Greene, 2012). Conversely, Baron and colleagues (2015) argued against this model. They found that the link between CRT responses and utilitarian judgments was unreliable (see also Cova et al., 2018), that the link between new CRT questions without lures and utilitarian judgments was about as reliable, and that valuing actively open-minded thinking also predicted utilitarian judgments. Hence, they concluded that the impact of the CRT on dilemma judgments is not explained by overcoming unreflective responses (e.g., responding reflectively on CRT items with lures) as well as it is explained by the extensiveness of reflection (e.g., actively open-minded thinking and CRT items without lures).

Yet, analyses of conventional sacrificial dilemmas may yield correlations between reflection and dilemma responses that appear "labile" (Baron et al., 2015, p. 279), when in fact they are quite stable. Moreover, it may be that different measures of reflection have different relationships with dilemma decisions_-relationships that may be obscured in analyses of conventional sacrificial dilemmas. Conventional sacrificial dilemmas treat deontological and utilitarian considerations as diametrically opposite. So conventional analyses cannot determine whether a given measure, such as the CRT, predicts utilitarian inclinations independently of deontological inclinations; moreover, such analyses remain insensitive to factors that predict

\footnotetext{
${ }^{1}$ Note that utilitarian inclinations as assessed here correspond roughly to the 'minimalist' orientation described by Royzman, Landy, and Leeman (2014) — both reflect perceptions that acting to maximize outcomes in morally appropriate rather than mandatory. This difference reflects inconsistency regarding the ways researchers employ the meaning of the term 'utilitarian judgments' (see Conway et al., 2018).
} 
increases in both inclinations, thereby cancelling out for conventional sacrificial dilemma judgments (e.g., Reynolds \& Conway, 2018).

To overcome these limitations and clarify previous findings, we employed both conventional analysis and process dissociation (PD), which can better distinguish deontological and utilitarian inclinations from other factors (Conway \& Gawronski, 2013). We also assessed all measures of reflective thinking employed by Baron and colleagues (2015). The increased sensitivity afforded by PD allowed us to clarify the robustness of the relationship between reflection and dilemma responding. Moreover, PD allowed us to clarify how each measure of reflection relates to each dilemma response tendency. Two studies suggest that arithmetic reflection, as captured by measures like the CRT, primarily predicts utilitarian tendencies, but logical reflection, as captured by measures containing syllogisms, predicts both deontological and utilitarian tendencies.

\section{Moral Dilemmas}

Sacrificial dilemmas involve causing some harm to maximize overall outcomes, such as in the nurse dilemma described above or in the famous trolley problem where one can redirect a runaway trolley to kill one person to save five others. Although philosophers originally devised moral dilemmas to indirectly test how well their intuitive responses obey certain moral principles (e.g., Foot, 1967, 1995; Thomson, 1986), subsequent theorists have treated ordinary peoples' decisions to accept or reject causing harm in sacrificial dilemmas as compatible with and possibly involving simpler versions of those moral principles (e.g., Greene et al., 2004; Conway, Goldstein-Greenwood, Polacek, \& Greene, 2018a). Specifically, accepting harm that maximizes outcomes is said to align with utilitarianism, where the moral appropriateness of actions depends on their consequences - the goal is to increase overall wellbeing (Mill, 1861/1998; Norcross, 
2006). ${ }^{2}$ Conversely, decisions to reject causing harm (even when doing so results in greater total harm) are said to align with deontology, where the moral appropriateness of actions hinges on their accordance with moral maxims, independent of consequences (Kant, 1785/1959; Alexander \& Moore, 2016). Hence, theorists often treat dilemma responses as definitionally 'deontological' or 'utilitarian' even though decision-makers may not evince explicit or implicit commitment to such moral theories. ${ }^{3}$

Although dilemmas were developed by philosophers, considerable empirical research examines the psychological mechanisms that underpin dilemma responses (see Greene, 2013). The most prominent model of psychological factors suggests that deontological judgments are driven primarily by negative emotional responses to causing harm, whereas utilitarian responses are driven primarily by cognitive reflection about consequences (Greene et al., 2001; Greene, 2007, 2013; for updates see Cushman, 2013; Crockett, 2013). The original 'hard' version of this theory further stipulated that deontological judgments occur rapidly and intuitively, but evidence does not support this contention (e.g., Baron, Gürçay, Moore, \& Starcke, 2012; Koop, 2013). Yet, there remains considerable support for the 'softer' dual process claim that deontological judgments involve relatively more affective processing, whereas utilitarian judgments involve relatively more cognitive deliberation (e.g., Bartels, 2008; Conway \& Gawronski, 2013;

\footnotetext{
${ }^{2}$ Utilitarian ethics involve both minimizing total harm and pursuing impartial concern for the greater good, but sacrificial dilemmas appear to reflect the former, not the latter (Conway et al., 2018). Some theorists argue that this is a limitation of sacrificial dilemmas (e.g., Kahane et al., 2015, 2018), but this argument assumes that the goal of dilemma research is to describe the psychology behind utilitarian philosophical ideals, when originally dilemma research was designed to examine the psychology behind a particular set of decisions that happen to definitely qualify as utilitarian, and were never intended to capture the entirety of utilitarian thinking (Greene, 2013; Conway et al., 2018a).

${ }^{3}$ Dilemma decisions may be descriptively consistent with a given philosophy, but this does not mean they were caused by general commitments to that philosophy. Instead, dilemma decisions could express a variety of motivations, some of which are plausibly related to the more elaborate views endorsed by philosophers and some of which are not. Hence, calling something a utilitarian decision does not imply that decision-maker generally endorses utilitarian ideals, but rather that the judgment is required by utilitarianism and likely involves simple cost-benefit or greater good thinking that resembles utilitarian reasoning (see Kahane et al., 2015, 2018; Conway et al., 2018a).
} 
Gleichgerrcht \& Young, 2013; Greene, Morelli, Lowenberg, Nystrom, \& Cohen, 2008; Moore, Clark, \& Kane, 2008; Patil \& Silani, 2014; Patil et al., 2019).

That said, the picture is undoubtedly more complex. Not all labs have replicated such effects (e.g., Gawronski, Conway, Friesdorf, Armstrong, \& Hütter, 2017), some find links between deliberative processing and deontological response tendencies (e.g., Gamez-Djokic \& Molden, 2016; Körner \& Volk, 2014; McPhetres et al., 2018), and others demonstrate links between affective concerns and utilitarian response tendencies (e.g., Reynolds \& Conway, 2018). Further, models focused on such basic processes ignore higher-order processes like strategic selfpresentation (Rom \& Conway, 2018). However, the preponderance of evidence suggests that the dual-process model is not so much incorrect as merely incomplete. Although other processes play a role, ultimately considerable evidence supports the claim that deontological responses involve relatively more affective processing about harmful actions, whereas utilitarian responses appear to involve relatively more deliberative reasoning about outcomes (e.g., Bartels, 2008; Conway et al., 2018a). Thus, we anticipated that most measures of reflective thinking would predict utilitarian responses-yet, we also suspected that some measures of reflective thinking may predict deontological responses.

\section{Reflection and Dilemma Judgments}

Philosophers have long suggested that reflection is an important component of utilitarian judgment (e.g., Sidgwick, 1874/1962), and considerable evidence supports this view. For example, people who make utilitarian judgments tend to score high on measures of reflective (vs. intuitive or unreflective) thinking (Bartels, 2008), working memory capacity (Moore, Clarke, \& Kane, 2008), deliberative approaches to morality (Fleishmann, Lammers, Conway, \& Galinsky, 2017), performance on the CRT (Baron et al., 2015; Byrd, 2019; Paxton, Bruni, \& Greene, 
2014), actively open-minded thinking (Baron et al., 2015), and demonstrate activation in brain regions associated with cognitive processing (Greene et al., 2004). Moreover, situational manipulations that facilitate deliberation increase utilitarian responding (Bartels, 2008; Paxton et al., 2012; cf. Cova et al., 2018), and situations that impair deliberation tend to reduce (Conway \& Gawronski, 2013; Trémolière, De Neys, \& Bonnefon, 2012) or slow utilitarian responding (Greene, Morelli, Lowenberg, Nystrom, \& Cohen, 2008) — at least until the trade-off ratio becomes extreme (e.g., sacrifice 1 to save 5000, Trémolière \& Bonnefon, 2014). Thus, a preponderance of evidence upholds the link between utilitarian responses and reflection. Indeed, forthcoming meta-analyses find positive correlations between measures of reflective reasoning and utilitarian judgments (Hannikainen \& Cova, 2019; Reynolds, Byrd, \& Conway, 2019).

Yet, critics have also challenged the link between reflection and utilitarian dilemma judgments. Replications of Paxton and colleagues (2012) failed to obtain converging evidence that priming reflective thinking increased utilitarian judgments (Cova et al., 2018; Paxton, Bruni, \& Greene, 2014), and Gawronski and colleagues (2017) failed to replicate the earlier finding from Conway and Gawronski (2013) that cognitive load reduces outcome-focused responding, albeit using a different set of dilemmas. More relevant to this paper's primary interest, Baron and colleagues (2015) presented five studies assessing the links between measures of reflection, responses to moral dilemmas, ${ }^{4}$ and philosophical commitments. ${ }^{5}$ They found that CRT

\footnotetext{
${ }^{4}$ Baron and colleagues assessed both 'number' dilemmas that entail administering harm to prevent greater total harm, and 'rule' dilemmas that pit a deontological against a utilitarian rule. Only number dilemmas correspond to the kinds of sacrificial dilemmas employed in the current work because not all rule dilemmas involve causing harm, and thus lay people may view them in a very different light (see Janoff-Bulman, Sheikh, \& Hepp, 2009; Conway et al., 2018). Thus, we limit our claims to discussion of sacrificial dilemmas (i.e., 'number' dilemmas) only.

${ }^{5}$ Again, the psychological processes that drive dilemma judgments need not entail endorsement of the philosophical positions that dilemmas are said to accord with (Kahane et al., 2018; Conway et al., 2018). We focus here on the link between reflection and dilemma responses per se and remain agnostic about links between reflection and endorsement of any philosophy.
} 
performance often, but somewhat inconsistently, predicted acceptance of harm on sacrificial dilemmas, concluding that the correlation between reflection and utilitarian dilemma judgments is "labile and not always found" (Baron et al., 2015, p. 279). Baron and colleagues also investigated the original 'hard' dual process claim that utilitarian responses require overcoming a rapid initial intuition to select the deontological response (see also Bago \& De Neys, 2018). They argued that if this were the case then there ought to be higher correlations between utilitarian responding and variants of the CRT that contain 'lures' - tempting but incorrect intuitive responses - than variants of the CRT without lures, as the former would better assess dispositions to overcome initial intuitions. Yet, they found that utilitarian responses correlated similarly with both of these CRT variants. They argued that such findings indicate that utilitarian judgments need not entail overcoming an initial intuitive response. Rather, utilitarian judgments correlate with CRT performance indirectly through shared variance with a third construct: actively open-minded thinking (AOT). AOT assesses two components: ambition to reason extensively and openness to change one's mind (Stanovich \& West, 1997; Baron, 1995). Baron and colleagues conclude that utilitarian responses are better explained by the former, extensiveness component of AOT than the latter, openness component of AOT, given their earlier conclusion that utilitarian judgments do not seem to involve changing initial responses.

However, the conventional sacrificial dilemmas Baron and colleagues used to support this argument have a limitation: they measure the relative rather than the absolute strengths of competing considerations. Historically, many deontologically-minded philosophers considered both "bad results" or "disastrous consequences" and paradigmatically deontological principles in their moral reasoning (e.g., Kant, 1797/1991, p. 53; Ross, 1930/2003, p. 18; see also Alexander \& Moore, 2016; Johnson, 2019a, 2019b). Alas, conventional sacrificial dilemmas measure only 
the relative difference between these consequential and deontological considerations rather than the absolute contribution of each consideration (Conway \& Gawronski, 2013). So when something covaries with both deontological and utilitarian considerations in the same direction and to the same degree, then the relative difference is zero, and analysis of the conventional sacrificial dilemmas does not detect the effect, thereby missing or distorting results that other techniques can detect (e.g., Reynolds \& Conway, 2018; Conway et al., 2018a, 2018b). In the current work, we use these more sensitive techniques to dissociate absolute contributions of competing moral considerations and their relationship with measures of reflection, including CRT and AOT.

Arithmetic measures of reflection. One widely used arithmetic measure of reflection is the Cognitive Reflection Test (Frederick, 2005). The original CRT includes three rudimentary math questions that are designed to lure participants into a particular, incorrect answer. For example, one question is as follows. " $\mathrm{A}$ bat and a ball cost $\$ 1.10$ in total. The bat costs $\$ 1$ more than the ball. How much does the ball cost?" Most participants were lured to responding "10 cents." Yet, that response is incorrect: it satisfies the prompt's first condition, but not the prompt's second condition. Frederick labeled such lured incorrect responses as 'intuitive,' but subsequent work has called into question whether this label is appropriate, given that lured responses do not correlate with other measures of intuition (Pennycook, Cheyne, \& Koehler, 2015). Hence, we employ the term reflective to describe a correct response to a CRT question, and lured to describe the lured, incorrect response to a CRT question, which is importantly distinct from other possible incorrect responses to a CRT question. ${ }^{6}$

\footnotetext{
${ }^{6}$ Since the CRT contains only three items and it has been accepted as a valid measure of reflection, it is among the most commonly used measures of its kind. However, some are worried that as more participants are exposed to the CRT, they will learn to pre-empt or even overcome its lures (Haigh, 2016). So researchers have responded by
} 
Although Frederick (2005) designed the CRT as a measure of general reflective ability, he expressed some concern that it is confounded with numeracy. Numeracy, short for numerical literacy, refers to the ability to comprehend and process mathematical information (Reyna, Nelson, Han, \& Dieckmann, 2009). Because the CRT involves comprehending and processing mathematical information, some researchers have worried that the CRT is just another numeracy test (Campitelli \& Labollita, 2010). However, subsequent work indicates that while CRT performance does correlate with numeracy, the CRT is not reducible to a numeracy test (Liberali, Reyna, Furlan, Stein, \& Pardo, 2012; Patel, 2017; Primi, Morsanyi, Chiesi, Donati, \& Hamilton, 2016) — it also measures the inhibition of default responses (e.g., Campitelli \& Gerrans, 2014), miserly reasoning (Toplak, West, \& Stanovich, 2011), and actively open-minded thinking (Szaszi, Szollosi, Palfi, \& Aczel, 2017).

One might wonder how the numeracy portion of CRT scores can explain correlations between CRT performance and utilitarian judgments. People higher in numeracy tend to be more influenced by mathematical information in their environment (Reyna et al., 2009) and tend to direct donations where they benefit the greatest proportion of a population (Kleber, Dickert Peters, \& Florack, 2013). Many theorists have argued that utilitarian judgments involve some degree of mathematical calculus, as they involve weighing different numbers of lives and selecting the highest values (e.g., Greene et al., 2004). Moreover, past research finds links between utilitarian dilemma judgments and deliberation (e.g., Bartels, 2008; Moore, Clark, \&

creating new, and therefore less familiar, versions of the CRT (e.g., Ackerman 2014; Finucane \& Gullion 2010; Baron et al 2015; Oldrati, Patricelli, Colombo, \& Antonietti, 2016; Primi, Morsanyi, Chiesei, Donati, \& Hamilton 2016; Schtulman \& McCallum, 2014; Stieger \& Reips, 2016; Thomson \& Oppenheimer, 2016; Toplak, West, \& Stanovich, 2014; Trémolière, De Neys, \& Bonnefon 2014). More recent research has found that the concern about familiarity might have been overstated: CRT performance is robust, even after repeated exposures (Białek \& Pennycook, 2017; Meyer, Zhou, \& Frederick, 2018; Stagnaro, Pennycook, \& Rand, 2018; Welsh \& Begg, 2017). Nonetheless, in our studies, we used all arithmetic measures of reflection employed by Baron and colleagues (2015), including the original 3-item CRT. 
Kane, 2008; Greene et al., 2004). More recent work by Patil and colleagues (2019) found that more calculation-heavy model-based reasoning correlated with utilitarian and not the deontological response patterns. Taken together, this work suggests that arithmetic measures of reflection, such as the CRT, will correlate with utilitarian, but not deontological, response tendencies when these tendencies are assessed independently (Conway \& Gawronski, 2013).

Logical measures of reflection. Baron and colleagues (2015) found that utilitarian judgments correlated with not only arithmetic CRT variants, but also non-arithmetic measures of reflection. These measures assess participants' logical reasoning by asking participants if a syllogism is logically valid-i.e., if a set of premises support a conclusion. Some logical measures of reflection also measure belief bias: the tendency to evaluate a syllogism according to the believability of its conclusion instead of the logical validity of the syllogism (Evans, Barston, \& Pollard, 1983; Janis \& Frick, 1943; Oakhill \& Johnson-Laird, 1985; Markovits \& Nantel, 1989). Like the CRT, tests of belief bias lure participants into giving a particular incorrect response. A typical belief bias item presents two premises and asks participants about what logically follows from those premises. Some belief bias questions ask if believable conclusions follow from the premises-e.g., "If these two statements are true, can we conclude that Bill Gates is rich?"- but other belief bias questions ask if unbelievable conclusions follow from premises - e.g., "If these two statements are true, can we conclude that boats have wheels?" Moreover, some belief bias syllogisms present answers that are logically valid, whereas other belief bias syllogisms are logically fallacious. As a result, researchers can examine whether participants correctly indicate which syllogisms are logically valid versus invalid, both in cases where conclusions seem intuitively plausible and in cases where they do not. Thus, people who score high in logical reflection are adept at evaluating logical validity, whether or not the 
statements involved seem intuitively correct, an ability that requires deliberative processing (Oakhill \& Johnson-Laird, 1985; Markovits \& Nantel, 1989).

Given the findings described above linking deliberative processing to utilitarian responding (e.g., Bartels, 2008; Patil et al., 2019), including (most notably) Baron and colleagues' (2015) findings, one might expect that performance on measures of logical reflection will correlate with utilitarian but not deontological response tendencies when these are measured independently (Conway \& Gawronski, 2013). However, logical reflection may have a different relationship with dilemma judgments than arithmetic reflection does. Arithmetic and logical reflection appear to track somewhat different constructs: Research suggests that people who overcome lured responses on measures of logical reflection take longer to answer the relevant questions than people who fall for the lures; however, people who overcome lured responses on the CRT take no longer than people who fall for the lures (Stupple, Ball, Evans, \& Kamal-Smith, 2011; Stupple, Ball, \& Ellis, 2013).

Consider also that deontological theorists like Kant (1797/1991) envisioned deontological judgments arising from logical reflection about principles, reasons, and norms (Bennis, Medin, \& Bartels, 2010). In line with Kant's expectation, recent work has found that cognitive deliberation can contribute to deontological response tendencies (Gamez-Djokic \& Molden, 2016; Körner \& Volk, 2014; McPhetres, et al., 2018). Further, consider that dilemmas are designed to create conflict by posing two unappealing options and that conflict detection can trigger reflection (Pennycook, Fugelsang, \& Koehler, 2015). In line with this, recent work suggests that increasing conflict by inducing people to distrust their initial dilemma responses increases both deontological and utilitarian response tendencies, and this effect is mediated through increased ambivalence between answers (Conway et al., 2018b). Moreover, people who care deeply about 
harm — and, presumably, think more carefully about sacrificial dilemmas — score higher on both deontological and utilitarian inclinations (Reynolds \& Conway, 2018; Conway et al., 2018a); as do people who care about being moral (Conway \& Gawronksi, 2013). Conversely, reducing ability to understand and engage with dilemmas reduces both deontological and utilitarian response tendencies (Muda, Niszczota, Białek, \& Conway, 2017; Hayakawa, et al., 2017). Therefore, we expected that greater logical reflection would predict not only utilitarian response tendencies, but also deontological response tendencies. Thus, we expected that arithmetic reflection would have a different impact on dilemma judgments than logical reflection-but that this difference would be more detectable with process dissociation than with only conventional sacrificial dilemmas.

\section{Process Dissociation}

Existing work assessing the link between reflection and moral dilemma judgments relies on conventional sacrificial dilemmas, which confound motivations for one dilemma response with rejection of competing motivations for the other dilemma response. Alternatively, we employ process dissociation (PD) to assess absolute parameters for utilitarian and deontological response tendencies. PD is a content agnostic procedure designed to disentangle the impact of multiple influences jointly contributing to an outcome (Jacoby, 1991) and has been fruitfully deployed in much research (Payne \& Bishara 2009), including moral dilemmas (Conway \& Gawronski 2013). Unlike conventional sacrificial dilemmas, which attempt to measure only relative contributions of utilitarian and deontological considerations, PD dilemma analysis attempts to assess the absolute contribution of utilitarian considerations independently of the contribution of deontological and other considerations. 
Using PD to assess moral dilemma judgments involves assessing responses to both congruent and incongruent dilemmas. Incongruent dilemmas correspond to conventional sacrificial dilemmas. Rejecting harmful action in incongruent dilemmas is said to align with paradigmatically deontological ethics, where actions are evaluated according to categorical moral norms (e.g., Kant, 1797/1991, see Alexander \& Moore, 2016). Conversely, accepting harmful action in incongruent dilemmas (thus mitigating overall harm) is said to align with paradigmatically utilitarian ethics where the morality of actions are determined by their consequences (e.g., Mill, 1861/1998, see Alexander \& Moore, 2016). Congruent dilemmas are worded similarly, and propose causing the exact same harm, but the outcome of that harm no longer maximizes overall wellbeing. Indeed, rejecting harmful action in congruent dilemmas also leads to the overall optimal outcome. So rejecting harmful action in congruent dilemmas is said to align with both deontological and utilitarian ethics, whereas accepting harmful action in congruent dilemmas not only violates norms about directly causing harm but also makes the world worse, and is therefore said to be anathema to both deontological and utilitarian ethical considerations.

PD computes independent utilitarian and deontological parameters by distinguishing multiple response patterns across both congruent and incongruent dilemmas (Figure 1). Although named 'deontological' and 'utilitarian,' consistent with the historical terminology in the field, we reiterate that these parameters do not represent explicit commitment to these philosophical positions (Kahane et al., 2015, 2018; Conway et al., 2018a); instead they refer to two response patterns: a pattern of not causing harm regardless of consequences (the deontology parameter), and a pattern of minimizing overall harm even when that requires directly causing some harm (the utilitarian parameter). We combined participant responses to incongruent and congruent 
dilemmas and employed the six formulae from Conway and Gawronski (2013), to algebraically compute a utilitarian and deontological parameter score for each participant (see Appendix).

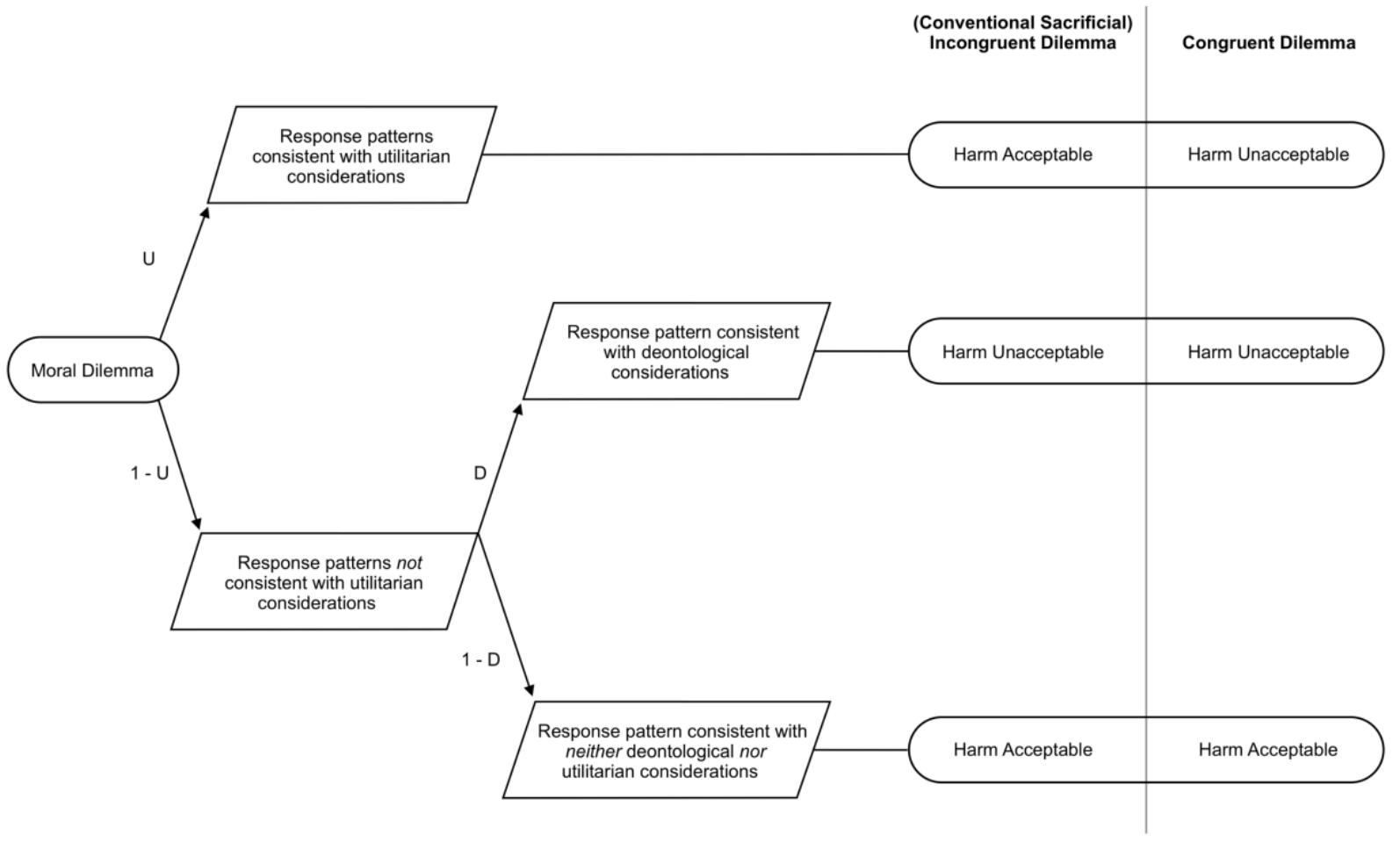

Figure 1. Processing tree illustrating how the Utilitarian (U) and Deontological (D) parameters are derived from responses to congruent and incongruent moral dilemmas using process dissociation. 
A growing body of work corroborates the utility of process dissociation for enhancing insight into the psychology of dilemma judgments. PD both allows for clarifying ambiguous findings and for increased sensitivity to detect effects that remain invisible to conventional sacrificial dilemma analyses. By assessing utilitarian and deontological response tendencies independently, researchers can disambiguate whether third factors impact one or the other process. For instance, multiple researchers have noted gender differences in dilemma responses and interpreted them as men scoring higher in utilitarian responses (e.g., Fumagalli et al., 2010; Arutyunova, Alexandrov, \& Hauser, 2016), but process dissociation reveals that in fact men and women score similarly in terms of utilitarian tendencies; in fact, most of the variance in gender differences reflects higher deontological response tendencies among women than men (Armstrong, Friesdorf, \& Conway, 2018; Friesdorf, Conway, \& Gawronski, 2015). Likewise, some conventional sacrificial dilemma analyses have suggested that utilitarian responses merely express psychopathy, egoism, and other antisocial personality traits (e.g., Bartels \& Pizarro, 2011; Kahane et al., 2015). However, PD includes congruent dilemmas and then excludes the patently non-deontological and non-utilitarian responses of accepting harm on these congruent dilemmas from both the utilitarian and deontological parameters (Figure 1). This more careful PD analysis finds that psychopathy, egoism, and antisociality either do not correlate with or anticorrelate with both the deontological and utilitarian parameters (Conway et al., 2018a). In other words, conventional sacrificial dilemmas confound psychopathic, egoistic, and antisocial responses with more pro-social, utilitarian responses in ways that PD dilemma analyses do not.

Similarly, PD can clarify the link between reflection and moral dilemma responses. One might ask why reflection only sometimes correlates with utilitarian responses (Baron et al., 2015). It might be that reflection, like need for cognition, typically correlates with only the 
utilitarian response pattern (Conway \& Gawronski, 2013). Or it might be that reflection, like emotion regulation, empathic concern, and religiosity, correlates not with the utilitarian response pattern, but the deontological response pattern (Ibid.; Conway et al., 2018a; Lee \& Gino, 2015; Park, Kappes, Rho, \& Van Bavel, 2016). Or, it could be that reflection correlates positively with both deontological and utilitarian response patterns, but the correlation with the utilitarian pattern is sometimes stronger. Conventional sacrificial dilemma analysis cannot distinguish these possibilities, but PD dilemma analysis can.

More importantly, PD has proven useful for detecting effects in the case of suppression, when a single variable has multiple competing impacts that largely cancel out. For example, Miller and colleagues (2014) found that outcome aversion - aversion to witnessing others suffer in agony - failed to predict conventional sacrificial dilemma responses. Reynolds and Conway (2018) replicated this finding using conventional sacrificial dilemmas, but their PD analysis revealed that outcome aversion positively predicted both the deontology and utilitarian parameters - these dual positive effects cancelled out in conventional sacrificial dilemmas that treat deontological and utilitarian responses as opposites.

Similar suppression effects on moral dilemma judgments have been demonstrated for moral identity internalization (e.g., Conway \& Gawronski, 2013), power (Fleishmann et al., 2017), self-control (Maranges et al., 2018), language processing (Hayakawa et al., 2017), moral conviction about harm (Conway et al., 2018a), and distrust mindsets (Conway et al., 2018b). Therefore, suppression is far from rare. Note that both partial and complete suppression are possible. Complete suppression occurs when the size of two competing effects are similar, so they cancel out completely; partial suppression occurs when one effect is substantially larger than the other, leading to a small, unreliable effect on conventional sacrificial dilemma 
responses. Due to statistical fluctuation, both partial and complete suppression may occur for the same sets of variables across multiple datasets (e.g., Reynolds and Conway, 2018), and is therefore particularly likely in cases where a theoretically meaningful effect appears intermittently across multiple datasets (e.g., Miller et al., 2014). Indeed, Baron and colleagues (2015) appear to face this exact same situation: reflection only predicted dilemma judgments intermittently. Thus, in the current work, we examined whether a PD analysis may reveal evidence of suppression regarding the influence of cognitive reflection on dilemma judgments. As noted above, we anticipated correlations with logical reflection would be suppressed in conventional sacrificial dilemmas, whereas we anticipated that arithmetic reflection would predict only the utilitarian parameter. In other words, by illuminating potential suppression effects, PD offered the opportunity to distinguish the link between each type of reflection and moral judgments.

\section{The Current Research}

Given that PD has demonstrated increased sensitivity to detect effects invisible to conventional sacrificial dilemma analyses, we employed PD to clarify the relationships between dilemma responding and cognitive reflection. Building on the work of Baron and colleagues (2015), we assessed all the measures of reflection they employed, but instead of measuring dilemma responses using only conventional sacrificial dilemmas, we employed PD dilemma analysis. ${ }^{7}$ For conventional sacrificial dilemmas, we expected to largely replicate the findings of Baron and colleagues (2015). However, armed with PD's greater clarity, we expected arithmetic

\footnotetext{
${ }^{7}$ Baron and colleagues also measured dilemma judgment response-times. Given that research shows only a weak correlation between response-times and other measures of reflection (Stupple, Pitchford, Ball, Hunt, \& Steel, 2017) and no significant difference in response-times between CRT takers whose first response is correct and CRT takers whose first response is incorrect (Szaszi, Szollosi, Palfi, \& Aczel 2017), we did not assess reaction times in the current work.
} 
reflection to predict utilitarian but not deontological response tendencies and logical reflection to predict both utilitarian and deontological response tendencies. In Study 1 we included all of the arithmetic and logical measures of reflection employed by Baron and colleagues (2015) and analyzed their relationship with both conventional sacrificial dilemma responses and PD dilemma response tendencies. In Study 2, we examined whether the effects in Study 1 would replicate and added measures of actively open-minded thinking and general numerical ability. Finally, we examined whether performance on a variety of reflection tasks mediate the impact of CRT performance on conventional sacrificial dilemma responses and on the PD parameters. For all studies, we report all manipulations, measures, exclusions, and we followed APA ethical guidelines. All data files and SPSS analysis syntax are available from the Open Science Framework: https://osf.io/y4mdw/

\section{Study 1}

\section{Method}

Participants. To obtain $99 \%$ power to detect a correlation of $r=.3$, GPower indicated that we would need 195 participants (Faul, Erdfelder, Lang, \& Buchner, 2007). We chose $r=.3$ because it is similar to the typical correlation between reflection and dilemma decisions in Baron and colleagues (2015). We oversampled, recruiting 282 American participants via a single run of Amazon's Mechanical Turk for $\$ 2.00$ per participant. We decided a priori to exclude all participants who failed an instructional manipulation check $(n=6)($ Oppenheimer, Meyvis, \& Davidenko, 2009) or who didn't complete all moral dilemmas $(n=0)$, leaving a final sample of 276 (143 male, 133 female, $M_{\text {age }}=35.25, S D=10.50,224$ identified as White, 18 as Black, 12 as Hispanic or Latino, 4 as Pacific Islander, 2 as American Indian or Native American, and 16 as other ethnicity). 
Procedure and materials. Participants completed all measures online, one item per page. Descriptive statistics such as Cronbach's alpha for all measures and zero order correlations between all measures are reported in Table 1 to facilitate comparisons with existing work as well as future meta-analyses. We do not interpret most of these correlations in the present work.

Cognitive reflection test. Participants completed all CRT items employed by Baron and colleagues (2015), some of which they developed themselves, and some of which they adapted from prior research (e.g., Finucane \& Gullion, 2010). ${ }^{8}$ These included the original CRT questions, new CRT questions with lures, and new CRT questions without lures.

Original CRT items. First, participants responded to the original, 3-item, Cognitive Reflection Test (Frederick, 2005). This includes the item regarding bats and balls presented above, as well as an item about widgets, and one about lily pads. Participants typed responses into a blank text box. ${ }^{9}$ We summed each participants' correct responses and lured responses independent of other incorrect responses.

New CRT with lures. Participants responded to three alternate CRT questions with lures, such as "If it takes 2 nurses 2 minutes to measure the blood pressure of 2 patients, how long would it take 200 nurses to measure the blood pressure of 200 patients?" We again summed all correct responses and all lured responses independent of other incorrect responses.

New CRT without lures. Participants also completed six more CRT questions without lures, such as, "If it takes 1 machine 10 min to make 5 widgets, how long would it take 10 machines to make 600 widgets?” Note that lured questions are designed to encourage an

\footnotetext{
${ }^{8}$ Baron and colleagues measured various batches of these items across different studies, but we assessed them all in each study.

${ }^{9}$ Although recent work suggests the CRT remains similarly reliable whether researchers employ open-ended or multiple format (Sirota \& Juanchich, 2018).
} 
immediate, unreflective response (e.g., two nurses and two minutes and two patients presents a misleading pattern), whereas CRT questions without lures are not designed to suggest an immediate, unreflective response. However, Baron and colleagues (2015) found similar results for CRT items regardless of the presence or absence of lures.

Belief Bias. Participants also responded to all belief bias questions employed by Baron and colleagues (2015), some of which were adapted from prior research (e.g., Markovits \& Nantel 1989). These included the original belief bias questions, consistent belief bias questions, and no-lure belief bias questions.

Original belief bias. Participants completed belief bias questions like the original belief bias questions in which the logical validity of the syllogism and the believability of its conclusion are incongruent, thus luring participants into evaluating syllogisms in terms of believability rather than logical validity. An example of an original belief bias item with this structure is this: "All flowers have petals. Roses have petals. If these two statements are true, can we conclude from them that roses are flowers?" (see Markovits \& Nantel 1989). Participants' correct responses were summed.

Consistent belief bias. Participants also evaluated three more syllogisms in which the validity of the argument and the believability of its conclusion are congruent, such as the following: "All business owners are rich. Bill Gates is a business owner. If these two statements are true, can we conclude from them that Bill Gates is rich?" Almost every participant reported the correct answer, presumably because the validity of the argument is consistent with the believability of its conclusion, meaning that the lured response is the same as the so-called 
reflective response. However, this means that variance was low for consistent belief bias items, making the reliability of the summed correct responses low. ${ }^{10}$

No-lure belief bias. Participants completed four more belief bias syllogisms, this time with arguments containing novel words like 'loolabay', 'wuzzies', 'shidos', 'reltas' — so that participants would not be lured into evaluating syllogisms according to the believability of their conclusions, given that participants do not have prior beliefs about the novel words. One no-lure belief bias question is as follows: "All laloobays are rich. Sandy is a laloobay. If these two statements are true, can we conclude from them that Sandy is rich?” Participants' correct responses on no-lure belief bias questions were summed.

Other syllogisms. Then participants assessed three more syllogisms to test for general logical competence with items such as this: "In a box, some red things are square, and some square things are large. What can we conclude? (a) Some red things are large. (b) All red things are large. (c) We can't conclude anything about red things and large things" (Johnson-Laird \& Bara, 1984). Participants' correct responses on the other syllogisms were summed.

Verbal reasoning items. Participants then completed 3 verbal reasoning items. These items come from Toplak \& Stanovich (2002), Böckenholt (2012), Krizo (2012), and Baron's personal correspondence with Edward Royzman, but can also be found in more recent work such as Thomson \& Oppenheimer (2016) and Sirota and colleagues (2018). One example of these items is as follows, “Ann's father has a total of five daughters: Lala, Lele, Lili, Lolo, and

\footnotetext{
${ }^{10}$ In some cases, the Cronbach's alpha for measures was quite low, but this is to be expected because a) these measures only employed few items, b) there is limited variance in responses, c) there is often no systematic reason to select a particular incorrect response (i.e., there is no lure, or the lure is congruent with the correct response). Moreover, we note that that we obtained a similar pattern of correlations between third variables and measures with both high and low alphas, suggesting that low alphas do not impair the ability to interpret these findings. Finally, low alphas make it more rather than less difficult to obtain significant correlations, and therefore the significant correlations we find should be considered more robust than less conservative alphas would suggest.
} 
What is the name of the fifth daughter?" Correct responses on these verbal reasoning items were summed.

Process dissociation dilemma battery. Participants then responded to 10 moral dilemmas, each with two versions, in a fixed random order (see Conway \& Gawronski, 2013; full text available at osf.io/nm7hy). Each dilemma described a harmful action that would achieve a particular outcome. Incongruent dilemmas correspond to conventional, high-conflict moral dilemmas (Koenigs et al., 2007), as causing some harm mitigates overall harm (for example, killing a baby will save many lives). Congruent dilemmas are worded identically to each incongruent dilemma, except that causing some harm does not mitigate overall harm (e.g., killing a baby will save others from hard labor). Participants considering harmful actions in each dilemma selected either yes, this harm is appropriate or no, this harm is not appropriate (Greene et al., 2001).

We totaled the number of times participants accepted causing some harm that mitigates overall harm on incongruent dilemmas as a relative measure of moral judgments: higher scores reflect more utilitarian than deontological responses, whereas lower scores reflect more deontological than utilitarian responses. This corresponds to the conventional dilemma analysis. Then we computed the utilitarian and deontological process dissociation parameters using participant response patterns across both incongruent and congruent dilemmas (see Figure 1 and Appendix).

Empathic concern. Finally, participants responded to the seven Empathic Concern items of the Interpersonal Reactivity Index (Davis 1980, 1983) on a 5-point scale ranging from Does not describe me well to Describes me very well.

\section{Results and Discussion}


Correlational analysis. First, we computed correlations between all measures in the study (see Table 1). This analysis revealed that, consistent with past work (Conway \& Gawronski, 2013), harm acceptance on conventional sacrificial dilemmas correlated positively with the utilitarian PD parameter and negatively with the deontological PD parameter, but the PD parameters themselves were not significantly correlated $(r=.08, p=.21)$. Common gender effects replicated: women scored substantially higher on the deontological PD parameter, whereas gender differences were negligible on the utilitarian PD parameter (e.g., Friesdorf et al., 2015). We also replicated previous findings showing that empathic concern correlated with the deontological but not utilitarian parameter (e.g., Conway \& Gawronski, 2013).

Moreover, measures of arithmetic and logical reflection (including lured responses) correlated as expected: performance on all variants of the CRT correlated with all measures of logical reflection (e.g., belief bias and other syllogism items). Likewise, lured incorrect responses on the CRT correlated negatively with all measures of logical reflection. These patterns suggest that all measures of reflection share some common variance (i.e., all assess some form of reflection), even though they demonstrate distinct patterns of correlations with dilemma responses. ${ }^{11}$

Moreover, consistent with Baron and colleagues' findings (2015), all variants of the CRT correlated positively with one another, whether the items were novel or not, and whether or not they included lures. Moreover, all showed similar patterns of relationships with other variables. Thus, all measures of the CRT seem to share common variance. However, unlike Baron and

\footnotetext{
${ }^{11}$ We further investigated how different measures of reflection might measure different components of reflection by conducting a factor analysis (see Table S1 in supplement). Although results partially confirmed our expectation of a two-factor solution corresponding to arithmetic and logical reasoning, they also revealed a third factor that may partially reflect lured responding. Moreover, we obtained a slightly different pattern from a parallel factor analysis in Study 2. Therefore, we interpret these results with caution.
} 
colleagues' findings, we found that the correlations between CRT items with lures were often (but not always) significantly larger than correlations between CRT items with lures and CRT items without lures. For example, correct responses on the original CRT correlated higher with correct responses on the new CRT (with lures), $r=.80$, than with correct responses on the new CRT without lures, $r=.44, z=10.22, p<.001$, controlling for the fact that the new CRT with and without lures themselves correlated $r=.62$. Thus, the presence versus absence of lures did not influence how well CRT items correlated with other measures but did influence how well CRT items cohered as a single construct_-partially corroborating albeit somewhat diverging from Baron and colleagues' results. 
Table 1. Correlations between Harm Acceptance on Incongruent and Congruent Dilemmas, the Utilitarian and Deontological Process Dissociation Parameters, Cognitive Reflection Test, Belief Bias, Syllogisms, Verbal reasoning items, Gender, and Age in Study $1(N=276)$

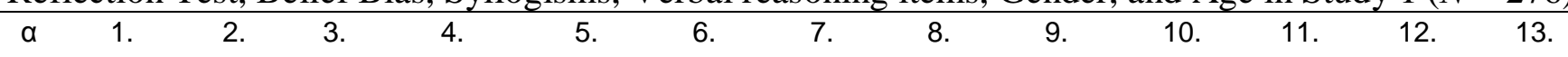

\section{Harm Acceptance on}

Incongruent Dilemmas

2. Harm Acceptance on $\quad-\quad .46^{\star *}$

Congruent Dilemmas

3. Utilitarian PD

Parameter

$-.57^{\star * *}-.47^{* \star *}$

4. Deontological PD

parameter

5. Original CRT,

\section{Correct}

6. Original CRT, Lured

$.80 \quad .17^{\star \star} \quad-.13^{\star} \quad .29^{\star \star \star} \quad .06$

7. New CRT, Correct

$\begin{array}{llllll}.77 & -.12 & .11 & -.22^{\star * *} & -.06 & -.92^{\star *}\end{array}$

8. New CRT, Lured

9. New No-Lure CRT,

$\begin{array}{lllll}.62 & -.14^{\star} & .11 & -.25^{\star \star \star} & -.04\end{array}$

$-.74^{\star \star} \quad .77^{\star \star \star} \quad-.79^{\star \star \star}$

\section{Correct}

10. Original Belief Bias

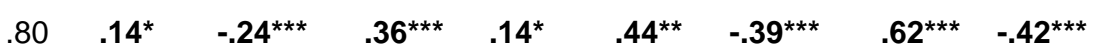

11. No-Lure Belief Bias

12. Consistent Belief

$.44^{\star *} \quad-.42^{\star * *}$

$.50^{\star \star \star} \quad-.40^{\star \star \star} \quad .52^{\star \star \star}$

Bias

13. Other Syllogisms

$\begin{array}{lllll}.06 & .07 & -.26^{\star \star \star} & .30^{\star \star} & .15^{\star}\end{array}$

$.25^{\star \star} \quad-.16^{\star \star}$

$.41^{\star \star \star}-.21^{\star \star \star}$

$.45^{\star * *}$

$.35^{\star \star \star}$

14. Verbal Reasoning

$\begin{array}{lll}.72 & .08 \quad-.18^{*}\end{array}$

$.25^{\star \star *} \quad .13^{\star}$

$.22^{\star \star} \quad-.18^{\star \star}$

$.36^{\star * *}-.20^{\star *}$

$.32^{\star \star \star} \quad .19^{\star \star} \quad .53^{\star \star \star}$

Items

15. Empathic Concern

$\begin{array}{lll}.19 & .10 & -.09\end{array}$

$.18^{\star \star} \quad .02$

$.36^{\star *} \quad-.32^{\star *}$

$.37^{\star \star \star}-.24^{\star \star \star}$

$.45^{\star \star \star} \quad .45^{\star \star \star} \quad .36^{\star \star \star} \quad .22^{\star \star \star}$

16. Gender $(m=1, f=2)$

$.89-.05 \quad-.18^{\star *}$

$.12 \quad .16^{\star \star} \quad-.01$

$.41^{\star \star \star}-. .41^{\star \star \star}$

$.38^{\star \star *}-.34^{\star \star *}$

$.23^{\star \star \star} \quad .16^{\star \star} \quad .14^{\star}$

$.24^{\star \star \star} \quad .08$

16. Age

$-.17^{\star \star} \quad-.13^{\star}$

$-.05$

$.16^{\star \star} \quad-.09-.11$

$.04 \quad-.04$

$-.06$

$.01 \quad .12$

$\begin{array}{lll}.14^{\star} & -.01 & -.03\end{array}$

$\begin{array}{lllllll}- & -.09 & -.28^{\star * *} & .17^{* *} & .27^{\star * *} & .12^{\star} & -.09\end{array}$

$-.15^{\star} \quad .10$

$\begin{array}{rrr}-.18^{\star \star} & -.18^{\star \star} & -.04\end{array}$

$.07 \quad-.13^{*}$

.04

$.24^{\star \star \star}$

Note: ${ }^{*} p<.05,{ }^{* *} p<.01,{ }^{* \star *} p<.001$ 
Conventional analysis. Conventional sacrificial dilemma analyses replicated previous work (e.g., Baron et al., 2015; Byrd, 2019; Paxton, Ungar, \& Greene, 2012; Royzman, Landy, \& Leeman, 2014): all measures of arithmetic reflection—namely, CRT performance-correlated positively with conventional sacrificial dilemma judgments where higher scores predict harm acceptance and lower scores predict harm rejection. This pattern emerged for correct performance on all variants of the CRT, whether they employed the original wording or novel wording, and whether they employed lures or not. Moreover, all lured CRT responses correlated negatively with harm acceptance on incongruent dilemmas (note that lured responses are not the direct opposite of correct responses, as only one particular incorrect response per item is the lured response).

Importantly, none of the non-arithmetic measures of reflection correlated significantly with conventional sacrificial dilemma responses: neither belief bias, nor other syllogisms, nor verbal reasoning items. This null pattern held for all variants of belief bias items, including original versions in which prior beliefs lure participants toward responses that conflict with logic, versions without such lures, and versions where prior beliefs lure participants toward responses that are consistent with logic. Thus, interpretations based only on conventional incongruent dilemmas would suggest that arithmetic, but not logical reflection predicts dilemma responding, and that arithmetic reflection predicts only utilitarian judgment. However, recall that PD is more sensitive than conventional analyses in cases of suppression where a single predictor has multiple competing influences that cancel out. Thus, we conducted a PD analysis to test for the possibility that correlations between dilemma judgments and logical reflection were suppressed in the conventional analysis. 
Process dissociation analysis. As anticipated, PD both clarified the findings in conventional sacrificial dilemma analyses and revealed evidence of suppression effects invisible to such conventional analyses. All measures of arithmetic reflection and responses to conventional sacrificial dilemmas loaded on the utilitarian parameter, $.22<r s<.37$, but not the deontological parameter, $-.06<r \mathrm{~s}<.07$, except in one case: Correct responses on new CRT items without lures correlated positively with the deontology parameter, though it also correlated positively with the utilitarian parameter, and this effect was stronger, $Z=2.84, p=004$. Thus, overall, arithmetic reflection was primarily associated with increased outcome-maximizing responses, but rarely with harm-rejecting responses, in line with dual process theory's predictions (Greene, 2015). Thus, PD clarified which parameter is impacted by effects detected via conventional methods, similar to past work (e.g., Friesdorf et al., 2015; Conway et al., 2018a).

Although PD corroborated and clarified conventional sacrificial dilemma analyses for arithmetic reflection, it revealed a very different picture of logical reflection than such conventional analyses. We found no significant correlations between measures of logical reflection and conventional incongruent dilemma responses. However, logical reflection anticorrelated with harm accepting responses on congruent dilemmas-responses that are inconsistent with deontological and utilitarian considerations. So PD revealed that these effects are composed of correlations that suppress one another in conventional incongruent dilemmas: performance on all belief bias items and other syllogism items positively correlated with both the utilitarian and deontological PD parameters. In other words, people who engage in logical reflection focus not only on improving outcomes — in line with the dual process model — but on rejecting opportunities to cause harm, especially when causing harm does not improve outcomes. 
Although this later finding does not support the dual process model, which posits that deontological responses are driven by emotion rather than reflection, this finding aligns with other recent work documenting the influence of cognitive deliberation on harm-rejecting (deontological) dilemma responding (Gawronski et al., 2017; McPhetres et al., 2018; GamezDjokic \& Molden, 2017; Körner \& Volk, 2014; Białek \& De Neys, 2017). Moreover, this finding aligns with classic views of deontological reflection about moral principles (e.g., Alexander \& Moore, 2016; Kant, 1797/1991). However, it should be noted that this finding does not rule out the possibility that such logical reflection is initially motivated by affective reactions to harm; other work confirms the role of such emotional reactions (e.g., Reynolds \& Conway, 2018; Szekely, Opre, \& Miu, 2015). Consistent with this argument and past work, the deontology parameter also correlated with empathic concern (e.g., Conway \& Gawronksi, 2013).

These findings indicate that both logical reflection and concern about harm increase deontological responses, and that different kinds of reflection can have different relationships with dilemma responding. To gauge confidence in this interpretation, we attempted to replicate these findings with a new sample in Study 2. Moreover, in Study 2 we added a measure of actively open-minded thinking (AOT) to examine whether this variable demonstrates the same pattern as arithmetic reflection, as argued by Baron and colleagues (2015), or whether it demonstrates the same pattern as logical reflection. We also added a validated measure of numeracy — the Berlin Numeracy Test — to better understand its relationship with reflection and dilemma judgments. Finally, we examined whether various measures of reflection would mediate the impact of arithmetic reflection on conventional sacrificial dilemma responses and on the PD parameters.

\section{Study 2}


Study 2 examined whether the findings of Study 1 would replicate with a new sample and added measures of numeracy (the Berlin Numeracy Test) and actively open-minded thinking (AOT). Baron and colleagues (2015) argued that AOT explained the relationship between CRT performance and harm acceptance on conventional sacrificial dilemmas. To examine this possibility, we examined whether AOT would mediate the effect of CRT performance on conventional sacrificial dilemmas, alongside other possible mediators, including numeracy, performance on the belief bias questions, other syllogism items, and verbal reflection items. Moreover, we conducted the same mediation analyses on the deontology and utilitarian PD parameters to assess whether some mediators carry variance from CRT performance to both PD dilemma parameters - effects that sometimes suppress one another in conventional sacrificial dilemmas (e.g., see Conway et al., 2018a).

\section{Method}

Participants. To obtain $99 \%$ power to detect a correlation of $r=.3$, GPower again indicated that would we need 195 participants (Faul et al, 2007). We slightly oversampled, recruiting 201 American participants via Amazon’s Mechanical Turk for \$2.00 (participants from Study 1 were prevented from participating in Study 2). We decided a priori to exclude all participants who failed an instructional manipulation check $(n=7)$ or who failed to complete all dilemmas $(n=3)$, leaving a final sample of 191 American participants (102 male, 87 female, 2 other, $M_{\text {age }}=36.87, S D=10.99,145$ identified as White, 20 as Black, 14 as Hispanic or Latino, 3 as Pacific Islander, 2 as American Indian or Native American, 6 as other ethnicity, and 1 no response). ${ }^{12}$

\footnotetext{
${ }^{12}$ Analyses controlling for gender employed only participants who identified as male or female.
} 
Procedure and materials. First, participants completed the measure of actively openminded thinking and the Berlin numeracy task, before completing all measures from Study 1. Descriptive statistics such as Cronbach's alpha for all measures and zero order correlations between all measures are reported in Table 2 to facilitate comparisons with existing work as well as future meta-analyses. We do not interpret most of these correlations in the present work.

Actively open-minded thinking. First, participants completed the 7-item Actively OpenMinded Thinking scale (Haran, Ritov, \& Mellers, 2013) by rating their agreement with statements such as "People should revise their beliefs in response to new information or evidence" on a 7-point scale ranging from Completely disagree to Completely agree.

Berlin numeracy test. Next, participants completed the 4-item Berlin Numeracy Test (Cokely, Galesic, Schulz, Ghazal, \& Garcia-Retamero, 2012). The BNT includes the question, "Imagine we are throwing a five-sided die 50 times. On average, out of these 50 throws how many times would this five-sided die show an odd number (1, 3 or 5)? (a) 5 out of 50 throws, (b) 25 out of 50 throws, (c) 30 out of 50 throws, or (d) None of the above." We summed correct responses to these questions for each participant.

Measures from Study 1. Next, participants also completed all measures from Study 1, which again demonstrated adequate reliability: Correct responses on the original CRT, lured responses on the original CRT, Correct responses on a new CRT, lured responses on a new CRT, correct responses on a new CRT without lures, correct original belief bias questions, correct consistent belief bias responses, and correct no-lure belief bias questions, correct responses on 
other syllogisms, correct responses on verbal reasoning items, and responses to the empathic concern section of the IRI. ${ }^{13}$

\section{Results and Discussion}

Correlational analysis. First, we computed correlations between all measures of Study 2 (see Table 2). This analysis revealed that, consistent with Study 1 and past work (e.g., Conway \& Gawronski, 2013), harm acceptance on conventional sacrificial dilemmas correlated positively with the utilitarian PD parameter and negatively with the deontological PD parameter, but the parameters themselves were only marginally correlated $(r=.14, p=.05)$. Once again, common gender effects replicated: women scored substantially higher on the deontological PD parameter, whereas gender differences were negligible on the utilitarian PD parameter (Friesdorf et al., 2015). However, unlike past work, empathic concern failed to correlate with either parameter (cf. Conway \& Gawronski, 2013).

\footnotetext{
${ }^{13}$ As in Study 1, the Cronbach's alpha for some measures was quite low, but this is to be expected for such measures, and we again obtained a similar pattern of correlations between third variables and measures with both high and low alphas, low alphas make it more difficult to obtain significant correlations, so we retain confidence in this pattern of findings despite the limited alphas.
} 
Table 2. Correlations between Harm Acceptance on Incongruent and Congruent Dilemmas, the Utilitarian and Deontological Process Dissociation Parameters, Actively Open-Minded Thinking, Berlin Numeracy Test, Cognitive Reflection Test, Belief Bias, Syllogisms, Verbal reasoning items, Empathic Concern, Gender, and Age in Study $2(N=191)$. a $1 .-2.0-3$

\begin{tabular}{|c|c|c|c|c|c|c|c|c|c|c|c|c|c|c|c|c|c|c|c|}
\hline & $\alpha$ & 1. & 2. & 3. & 4. & 5. & 6. & 7. & 8. & 9. & 10. & 11. & 12. & 13. & 14. & 15. & 16. & 17. & 18. \\
\hline $\begin{array}{l}\text { 1. Harm Acceptance on } \\
\text { Incongruent Dilemmas }\end{array}$ & & & & & & & & & & & & & & & & & & & \\
\hline $\begin{array}{l}\text { 2. Harm Acceptance on } \\
\text { Congruent Dilemmas }\end{array}$ & - & $.49^{\star \star *}$ & & & & & & & & & & & & & & & & & \\
\hline $\begin{array}{l}\text { 3. Utilitarian PD } \\
\text { Parameter }\end{array}$ & - & $.51^{\star \star \star *}$ & $-.50^{\star \star \star}$ & & & & & & & & & & & & & & & & \\
\hline $\begin{array}{l}\text { 4. Deontological PD } \\
\text { parameter }\end{array}$ & - & $-.74^{\star \star \star}$ & $-.89^{\star \star \star}$ & $.14^{*}$ & & & & & & & & & & & & & & & \\
\hline $\begin{array}{l}\text { 5. Actively Open-Minded } \\
\text { Thinking }\end{array}$ & .78 & .04 & $-.33^{\star \star \star}$ & $.36^{\star * *}$ & $.20^{\star *}$ & & & & & & & & & & & & & & \\
\hline 6. Berlin Numeracy Test & .43 & -.01 & $-.19^{\star}$ & $.18^{*}$ & .13 & $.31^{\star \star \star}$ & & & & & & & & & & & & & \\
\hline 7. Original $\mathrm{CRT}$, Correct & .78 & .13 & -.11 & $.24^{\star \star}$ & .04 & $.38^{\star \star \star}$ & $.33^{\star \star \star}$ & & & & & & & & & & & & \\
\hline 8. Original CRT, Lured & .74 & -.12 & .08 & $-.20^{\star \star}$ & -.03 & $-.35^{\star \star \star}$ & $-.30^{\star \star \star}$ & $-.94^{\star \star \star}$ & & & & & & & & & & & \\
\hline 9. New CRT, Correct & .70 & $.18^{\star}$ & -.12 & $.30^{\star * *}$ & .05 & $.37^{\star * *}$ & $.36^{\star \star \star}$ & $.83^{\star \star *}$ & $-.77^{\star \star \star}$ & & & & & & & & & & \\
\hline 10. New CRT, Lured & .52 & $-.14^{\star}$ & .05 & $-.20^{\star \star}$ & .01 & $-.36^{\star \star \star}$ & $-.32^{\star \star \star}$ & $-.78^{\star \star \star}$ & $.76^{\star \star \star}$ & $-.79^{\star \star \star}$ & & & & & & & & & \\
\hline $\begin{array}{l}\text { 11. New No-Lure CRT, } \\
\text { Correct }\end{array}$ & .83 & .14 & $-.24^{\star \star}$ & $.37^{\star *}$ & .12 & $.40^{\star \star *}$ & $.46^{\star \star \star}$ & $.50^{\star \star \star}$ & $-.48^{\star \star \star}$ & $.63^{\star \star \star}$ & $-.48^{\star \star \star}$ & & & & & & & & \\
\hline 12. Original Belief Bias & .82 & .07 & $-.25^{\star \star}$ & $.32^{\star \star \star}$ & $.16^{*}$ & $.36^{\star \star \star}$ & $.41^{\star \star \star}$ & $.47^{\star \star \star}$ & $-.46^{\star \star \star}$ & $.47^{\star \star \star}$ & $-.43^{\star \star *}$ & $.61^{\star \star *}$ & & & & & & & \\
\hline 13. No-Lure Belief Bias & .32 & -.01 & $-.44^{\star \star \star}$ & $.43^{\star \star \star}$ & $.30^{\star \star *}$ & $.40^{\star \star \star}$ & $.32^{\star \star \star}$ & $.31^{\star \star \star}$ & $-.29^{\star \star \star}$ & $.37^{\star \star \star}$ & $-.26^{\star \star \star}$ & $.46^{\star \star \star}$ & $.48^{\star \star \star}$ & & & & & & \\
\hline 14. Consistent Belief Bias & .36 & -.09 & $-.36^{\star \star \star}$ & $.27^{\star \star \star}$ & $.27^{\star \star \star}$ & $.23^{\star \star}$ & .121 & .14 & $-.16^{*}$ & $.16^{*}$ & -0.04 & $.25^{\star \star \star}$ & .14 & $.46^{\star \star \star}$ & & & & & \\
\hline 15. Other Syllogisms & .61 & -.03 & $-.22^{\star \star}$ & $.20^{\star *}$ & $.20^{\star \star}$ & $.32^{\star \star \star}$ & $.25^{\star \star}$ & $.28^{\star \star \star}$ & $-.29^{\star \star \star}$ & $.33^{\star \star \star}$ & $-.14^{*}$ & $.46^{\star \star \star}$ & $.45^{\star \star \star}$ & $.35^{\star \star \star}$ & $.22^{\star *}$ & & & & \\
\hline $\begin{array}{l}\text { 16. Verbal Reasoning } \\
\text { Items }\end{array}$ & .21 & .09 & .01 & .08 & -.08 & $.20^{\star \star}$ & $.15^{\star}$ & $.32^{\star \star \star}$ & $-.27^{\star \star \star}$ & $.25^{\star \star \star}$ & $-.26^{\star \star *}$ & $.20^{\star *}$ & $.16^{*}$ & $.18^{*}$ & .04 & .10 & & & \\
\hline 17. Empathic Concern & .89 & -.07 & -.09 & .02 & .05 & .07 & -.09 & -.04 & .07 & -.13 & .13 & -.03 & -.12 & .09 & .12 & .02 & .113 & & \\
\hline $\begin{array}{l}\text { 18. Gender } \\
(m=1, f=2)\end{array}$ & - & $-.20^{\star *}$ & $-.16^{\star}$ & -.04 & $.19^{\star \star}$ & -.07 & -.06 & -.10 & .09 & $-.16^{*}$ & .11 & $-.15^{\star}$ & -.11 & -.02 & .09 & -.05 & -.08 & $.24^{\star \star}$ & \\
\hline 19. Age & - & -.05 & $-.23^{\star \star}$ & $.18^{\star}$ & $.21^{\star \star}$ & .02 & -.11 & .08 & -.07 & .06 & .02 & .09 & -.01 & .14 & $.15^{\star}$ & $.16^{\star}$ & -.04 & .10 & .09 \\
\hline
\end{tabular}

Note: ${ }^{\star} p<.05,{ }^{\star \star} p<.01,{ }^{\star \star *} p<.001$ 
Replicating Baron and colleagues’ (2015) findings, CRT items with lures (Table 2) correlated with items without lures. However, the correlations between items with lures were often significantly larger than correlations between items with and without lures. For instance, correct responses on the original CRT correlated more with correct responses on the new CRT (with lures), $r=.83, p<0.001$, than with correct responses on the new CRT without lures, $r=$ $.50, p<.001-$ a significant difference, $z=6.19, p<.001$. This pattern suggests that the presence of lures has an impact on CRT responding, though performance on the CRT cannot be attributed to overcoming lures alone. Nonetheless, Study 2 replicated Baron and colleagues finding that the process of overcoming lures does not seem especially important for dilemma decision-making, as we obtained similar patterns between the PD parameters and CRT items both with and without lures.

More importantly, replicating another finding from Study 1, Study 2 found that arithmetic items were often more highly correlated with one another than with logical items. For example, correct responses on the new CRT (with lures) correlated higher with correct responses on the new CRT without lures, $r=.63, p<.001$ than with correct responses on other syllogisms, $r=$ $.33, p<.001-$ a significant difference, $z=3.86, p<.001$. This is further evidence that performance on arithmetic reasoning items partly measured something that logical reasoning items did not—despite some shared variance between these measures. ${ }^{14}$

Conventional analyses. More importantly, we replicated the Study 1 finding that some measures of arithmetic reflection correlated positively or marginally with harm acceptance on conventional sacrificial dilemmas even though others failed to significantly correlate. We also

\footnotetext{
14 To explore this possibility, we once again conducted factor analysis. This time, the factor structure that emerged fit our expectations for a two-factor solution with most arithmetic items loading on one factor, and most logical items on the other (see Table S2 in supplement).
} 
replicated the Study 1 finding that all logical measures of reflection (e.g., belief bias) failed to significantly correlate with conventional sacrificial dilemma judgments. Taken together, these results align with past work suggesting an imperfectly reliable link between reflection and harm acceptance on conventional sacrificial dilemmas (Baron et al., 2015; Cova et al., 2018). Indeed, Baron and colleagues (2015) complained that the correlations between reflection and conventional sacrificial dilemma responses were "small and labile" (p. 271), and subject to fluctuation across datasets - a common occurrence in the case of suppression (e.g., Reynolds \& Conway, 2018). To examine this possibility of suppression, we conducted PD analyses.

Process dissociation analyses. PD analyses clearly replicated Study 1: all arithmetic measures (i.e., CRT and BNT) correlated positively with the utilitarian, but not deontological, PD parameter. However, logical measures (i.e., belief bias items and other syllogism items) correlated positively with both the utilitarian and deontological PD parameters. Thus, consistent with Study 1, these findings suggest that arithmetic and logical reflection have distinct relationships with dilemma decisions, though these distinct relationships remain largely undetected in conventional sacrificial dilemma analyses.

That is, arithmetic reflection and numeracy correlated only with the utilitarian parameter, in line with dual process arguments suggesting that utilitarian judgments are not only more reflective, but more influenced by mathematical information. Conversely, logical reflection, including performance on belief bias tasks and other syllogisms, correlated with both parameters, suggesting that people adept at logic strove to both avoid causing harm and to improve outcomes. This finding suggests that some deontological responses may stem from reflection, in line with philosophical views of deontological ethics (e.g., Alexander \& Moore, 2016; Kant, 1797/1991) and recent empirical work (e.g., McPhetres et al., 2018). These conclusions from PD 
analysis conflict with earlier conclusions that the link between reflection and dilemma judgments is weak and inconsistent because the early conclusions are based solely on conventional incongruent dilemmas that overlook the potential for statistical suppression (e.g., Conway et al., 2018a, 2018b).

Mediation analyses. Baron and colleagues (2015) found a correlation between Actively Open-minded Thinking, CRT performance (both with and without lures), and dilemma judgments. On this basis, they argued that, "People are more likely to adopt [a utilitarian] approach if they are actively open-minded thinkers" rather than merely intuition-overriding thinkers (p. 279). We did not find a significant correlation between AOT and harm acceptance in conventional sacrificial dilemmas. However, we found a significant negative correlation between AOT and harm acceptance on congruent dilemmas - a response that goes against both deontological and utilitarian considerations. Once that non-deontological and non-utilitarian harm acceptance was dissociated from the PD parameters, we found that AOT positively correlated not only with the utilitarian parameter, but with the deontological parameter as well (i.e., another suppression effect). ${ }^{15}$

To clarify why our findings only partially fulfilled Baron and colleagues' expectations about AOT, CRT, and utilitarian judgment, we examined whether actively open-minded thinking, numeracy, belief bias, other syllogisms, or verbal reasoning tasks mediated the impact of arithmetic reflection on harm acceptance in conventional incongruent dilemmas, and on each

\footnotetext{
${ }^{15}$ Note that the correlation between AOT and the U parameter was marginally stronger than the correlation between AOT and the D parameter, $\mathrm{z}=1.78, \mathrm{p}=.074$. This relative difference in size suggests that some samples using this measure may obtain complete suppression for conventional sacrificial dilemma judgments, whereas other studies may find only partial suppression where the larger effect of AOT and U bleeds into a positive correlation between AOT and harm acceptance in conventional incongruent dilemmas, as in Baron and colleagues (2015). Similar fluctuation between partial and complete suppression has likewise emerged in related work (e.g., Reynolds \& Conway, 2018).
} 
PD parameter, controlling for age and gender. For each analysis, we employed the PROCESS macro in SPSS 22 (IBM Corp., 2013) to conduct three 10,000-iteration simultaneous mediation bootstrap analyses according to the procedures recommended by Preacher and Hayes (2004).

Mediation of CRT on conventional sacrificial dilemma judgments. The first analysis examined whether actively open-minded thinking, numeracy, belief bias, other syllogisms, or verbal reasoning tasks simultaneously mediated the impact of all correct CRT responses on conventional sacrificial dilemma judgments, controlling for age and gender (see Figure 2). There was no significant mediation, as all confidence intervals included zero. Consistent with past correlational findings (e.g., Paxton, Unger, \& Greene 2012), the direct effect of CRT performance significantly predicted harm acceptance on conventional incongruent dilemmas, $c$ ' $=0.02, S E=.01, \mathrm{CI}_{95}[.004, .028]$. 


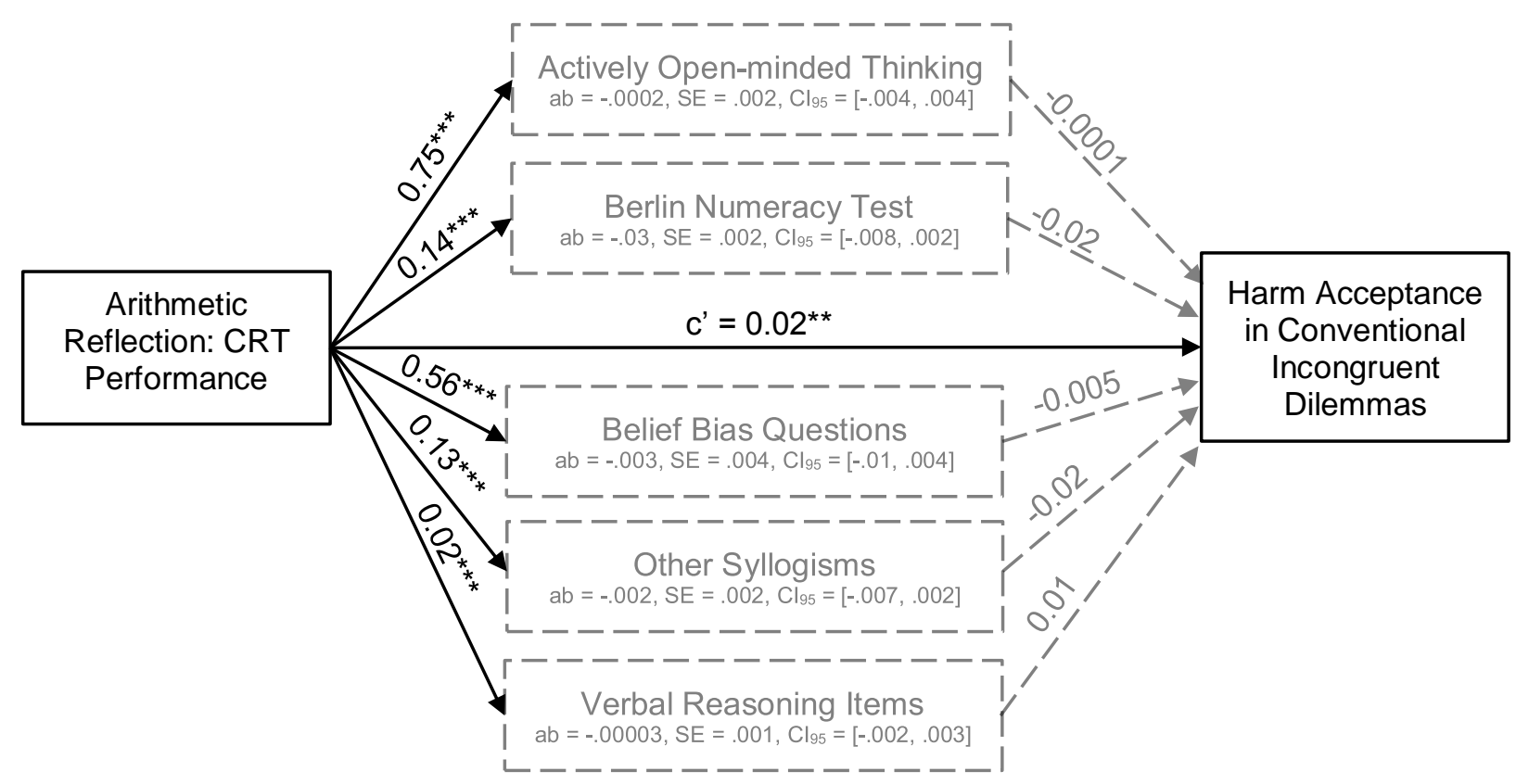

Figure 2. Only the direct effect from CRT performance to harm acceptance on conventional incongruent dilemmas was significant in the mediation analysis, controlling for age and gender. $* p<.05, * * p<.01, * * * p<.001$. 
Mediation of CRT on utilitarian PD parameter. The second mediation analysis examined whether actively open-minded thinking, numeracy, belief bias, other syllogisms, or verbal reasoning tasks simultaneously mediated the impact of all correct CRT responses on the utilitarian PD parameter, controlling for the deontological PD parameter, age, and gender (see Figure 3). ${ }^{16}$ There was no direct effect, but there were positive indirect effects of CRT performance on the utilitarian PD parameter through both actively open-minded thinking, $b=$ 0.01, $S E=0.002, \mathrm{CI}_{95}[0.004,0.011]$ and correct belief bias responses, $b=0.01, S E=0.004, \mathrm{CI}_{95}$ $[0.002,0.018]$. We obtained a similar pattern when controlling for the number of lured responses participants gave on the CRT.

These findings partially corroborate Baron and colleagues' (2015) claim that actively open-minded thinking accounts for the link between CRT performance and harm acceptance on conventional sacrificial dilemmas. However, belief bias performance also carried significant variance from CRT performance to the PD utilitarian parameter. Hence, people scoring higher on the CRT may demonstrate increased utilitarian inclinations partially because they engage in more actively open-minded thinking — perhaps about otherwise brutal actions — and because they excel at overcoming prior beliefs that conflict, logically, with certain moral principles. ${ }^{17}$

\footnotetext{
${ }^{16}$ We obtain similar findings without including covariates. Due to the covariates, these analyses provide results similar to those produced by structural equation modelling examining both parameters simultaneously (Hayes, Montoya, \& Rockwood, 2017).

${ }^{17}$ Note that the correlation between logical measures of reflection and the U parameter were reliably larger than the correlation between the same measures of reflection and the D parameter. However, these differences were not reliably significant, $1.1<z \mathrm{~s}<2.02, .02<p \mathrm{~s}<.14$ (Study 1) and $0<z \mathrm{~s}<1.65, .049<p \mathrm{~s}<.5$ (Study 2).
} 


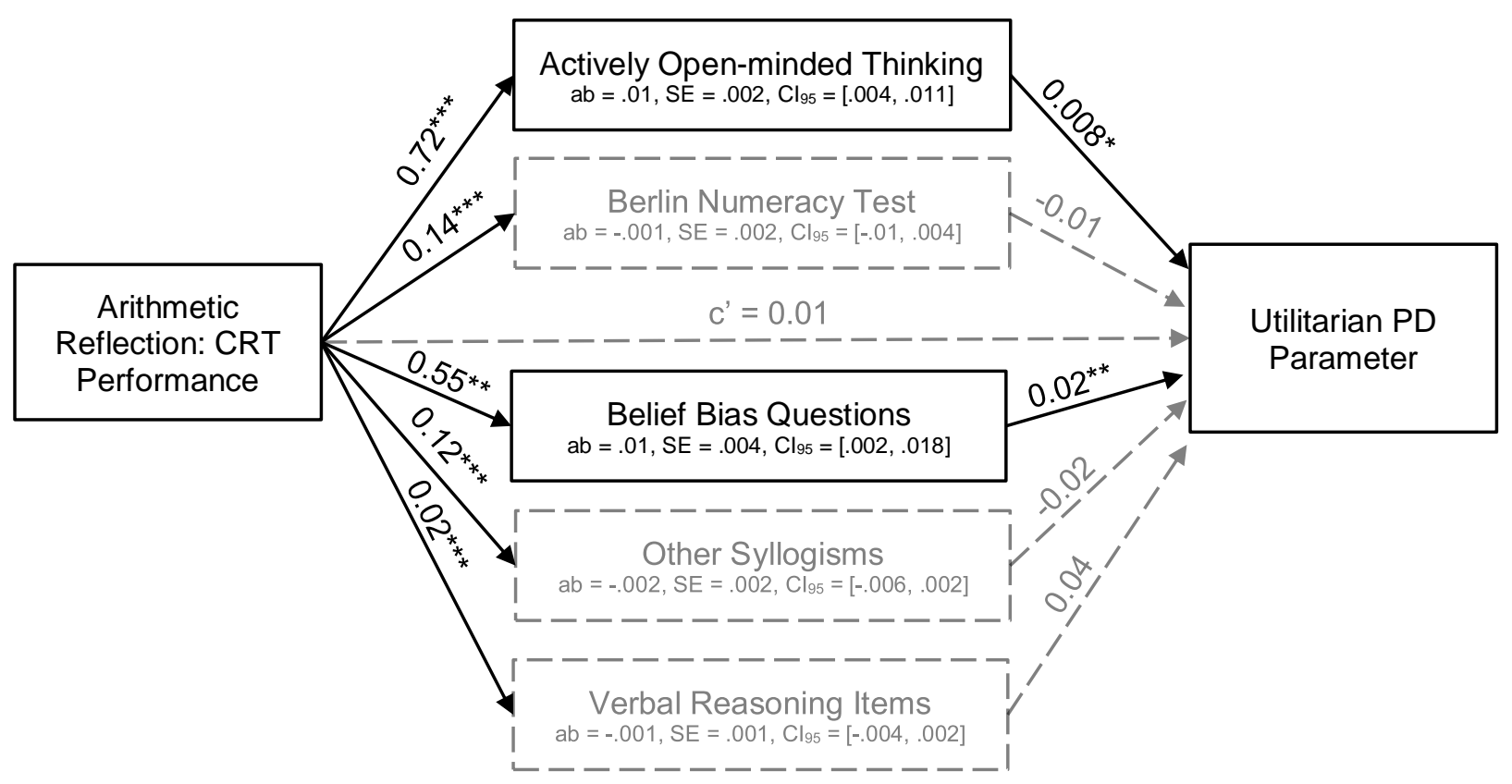

Figure 3. Increased actively open-minded thinking and performance on belief bias tasks mediated the effect of CRT performance on the utilitarian PD parameter, controlling for the deontological PD parameter, age, and gender. $* p<.05, * * p<.01, * * * p<.001$. 
Mediation of CRT on deontological PD parameter. The third mediation analysis examined whether actively open-minded thinking, numeracy, belief bias, other syllogisms, or verbal reasoning tasks simultaneously mediated the impact of all correct CRT responses on the deontological PD parameter, controlling for the utilitarian PD parameter, age, and gender (see Figure 4). Again, there was no significant direct effect, but there were significant indirect effects of CRT performance on the deontological PD parameter through both actively open-minded thinking, $b=0.003, S E=0.002, \mathrm{CI}_{95}[0.0001,0.008]$ and correct belief bias responses, $b=0.009$, $S E=0.004, \mathrm{CI}_{95}[0.003,0.02]$. We obtained the same mediation pattern when controlling for the number of lured responses participants gave on the CRT.

These findings contrast with Baron and colleagues' (2015) claims, as they demonstrate that actively open-minded thinking and overcoming belief bias not only mediate variance from CRT performance on increases in utilitarian responding, but also mediate increases in deontological responding. That is, people scoring higher on the CRT may demonstrate increased deontological inclinations partially because they engage in more creative open-minded consideration of brutal utilitarian actions, and because they excel at overcoming prior beliefs with logic. Hence, this pattern confirms that some cognitive deliberation contributes to deontological responding, a finding difficult to detect without use of process dissociation. Note that this analysis does not rule out the role of affective or emotional processes contributing to deontological responses; considerable other work documents important contributions from such processes (e.g., Reynolds \& Conway, 2018; Szekeley, Opre, \& Miu, 2015). But these findings align with other work indicating that cognitive deliberation plays a previously underappreciated role in deontological responding (e.g., McPhetres et al., 2018). 


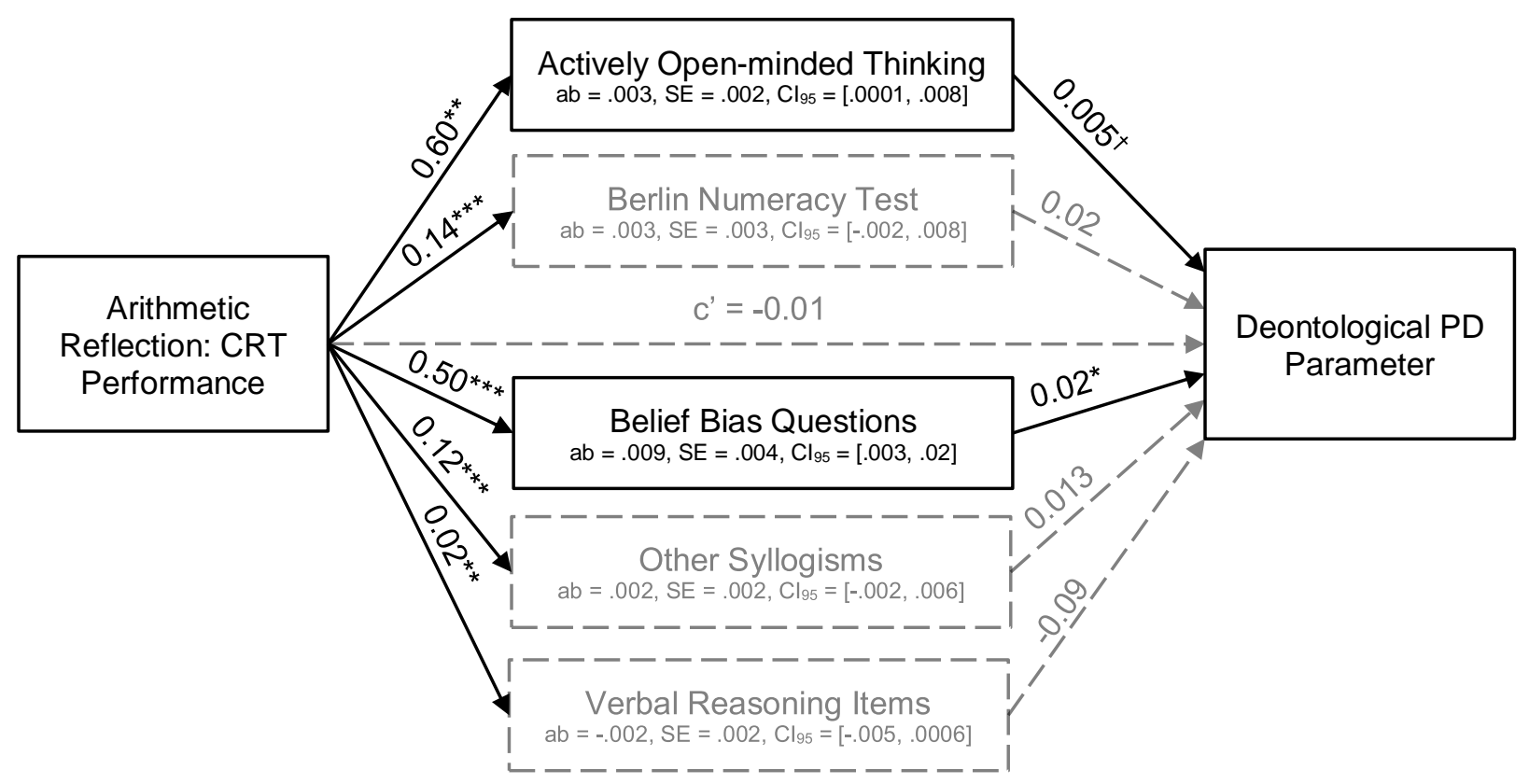

Figure 4. Increased actively open-minded thinking and performance on belief bias tasks mediated the effect of CRT performance on the deontological PD parameter, controlling for the utilitarian PD parameter, age, and gender. ${ }^{\dagger} p=0.08, * p<.05, * * p<.01, * * * p<.001$. 


\section{General Discussion}

In two studies, we clarified past work examining the association between reflection and sacrificial dilemma judgments. We replicated the finding that measures of reflection correlated with accepting harm in conventional sacrificial dilemmas, though consistent with past work these findings were sometimes labile (e.g., Baron et al., 2015; Moore et al., 2008; Paxton et al., 2012; Cova et al., 2018). Moreover, these findings suggested that the general category of 'reflection' might capture at least two distinct thinking styles. Arithmetic reflection, such as performance on the CRT, appears to capture the tendency to comprehend and process mathematical information that is incongruent with intuitively appealing lures. Logical reflection, such as performance on belief bias items, appears to capture the tendency to comprehend and process logical structure despite incongruent prior beliefs. Arithmetic reflection predicted conventional sacrificial dilemma judgment more clearly and robustly than did measures of logical reflection. Therefore, interpretations based on only conventional sacrificial dilemmas alone might conclude that mathematical but not logical reflection contributes to dilemma judgments.

However, we also employed process dissociation to reveal a more nuanced pattern of findings by assessing deontological and utilitarian response tendencies independently of one another and of other response tendencies. This analysis revealed that measures of arithmetic reflection correlated positively and robustly with utilitarian but not deontological response tendencies, consistent with dual process claims suggesting that reflection contributes more to utilitarian than deontological decision-making (e.g., Greene, 2013). This finding also dispelled concerns about possibly weak or labile connections between reflection and dilemma judgments when measured using techniques more sensitive than conventional methods. Moreover, this analysis revealed that logical measures of reflection were uniquely related to increases in both 
deontological and utilitarian response tendencies - dual relationships that largely cancelled out, leading to null effects on conventional sacrificial dilemmas, as in past work (e.g., Conway et al., 2018a; Reynolds \& Conway, 2018). Not only does this finding demonstrate the enhanced sensitivity of process dissociation to detect otherwise undetected effects, but it also accords with a growing body of work demonstrating that some kinds of reflection contribute to deontological decisions (e.g., Gamez-Djokic \& Molden, 2017; Körner \& Volk, 2014; McPhetres et al., 2018). Moreover, we found none of five mediator candidates, including actively open-minded thinking or performance on other reflection tasks mediated the direct effect of CRT performance on harm accepting responses to conventional sacrificial dilemmas. This finding contrasts somewhat with Baron and colleagues (2015), who suggested that actively open-minded thinking explains the relationship between CRT performance and harm acceptance in conventional sacrificial dilemmas. However, mediation using PD revealed that actively open-minded thinking, as well as performance on belief bias tasks (a measure of logical reflection) each mediated unique variance CRT performance on increases in both the deontology and utilitarian parameters. Again, these dual positive mediation relationships suppress one another, cancelling out for conventional sacrificial dilemma judgments. Hence, although correlational analyses demonstrate that CRT performance on other measures of arithmetic reflection predict increases in utilitarian but not deontological responses directly, to the degree that such measures share variance with measures of logical reasoning, they indirectly predict increases in both response tendencies. Hence, the role of reflection in moral decision-making is more complex than previously realized, and techniques such as process dissociation are required to clarify this complexity.

\section{Theoretical Implications}


Reflection \& Dilemma Judgment. These findings clarify a number of important theoretical issues. First, they provide the first demonstration of which we are aware that multiple categorically different types of reflection contribute to dilemma decision-making in different ways. Specifically, arithmetic reflection, such as CRT performance (on all variants, whether original or novel, whether lured or without lures), avoidance of CRT lured answers, and performance on the Berlin numeracy task, all predicted increases in utilitarian but not deontological responding, in line with dual process claims. In other words, more numerate individuals may be more influenced by the arithmetic features of dilemmas (Reyna et al., 2009) than other individuals.

However, non-arithmetic measures of reflection, such as belief bias tests, syllogisms, and actively open-minded thinking items, predicted increases in both the utilitarian and deontological parameters. Thus, arithmetic reflection might be related to dilemma judgments in a way that logical reflection is not. So theorists might benefit from considering such differences rather than pooling all measures of reflection when analyzing the relationship between reflection and dilemma judgments.

Dual process model. Second, these findings partially support and partially contradict the dual process model claim that cognitive deliberation contributes more to utilitarian than to deontological judgments (e.g., Greene, 2013). Findings examining mathematical reflection appear to largely corroborate this distinction, given their robust association with the utilitarian but not deontological parameter. However, the findings assessing logical reflection clearly indicate that reflection can and does contribute to deontological dilemma decisions, corroborating a growing body of work that also finds an impact of deliberation on deontological decisions (e.g., McPhetres et al., 2018). 
Therefore, these findings suggest revisions to the dual process model: both utilitarian and deontological judgment may arise via reflection, but utilitarian judgment may be more influenced by "moral calculations" than deontological judgments (Greene et al., 2004, italics added). In other words, people who make utilitarian decisions may be more likely than others to incorporate calculations about predicted outcomes into ethical decisions. In line with this possibility, Patil and colleagues (2019) recently demonstrated that performance on the Daw twostep task uniquely correlates with the utilitarian, but not the deontological parameter. This sequential decision task distinguishes computationally-demanding model-based evaluations based on calculations about consequences from reflexive model-free evaluations based solely on past habituation (Daw, Gershman, Seymour, Dayan, \& Dolan, 2011; Kool, Cushman, \& Gershman, 2016). Previous theorizing has linked utilitarian dilemma responses to model-based decision-making and deontological dilemma responses to model-free decision-making (Crockett, 2013; Cushman, 2013); the present findings are consistent with this theory. However, the current findings also suggest that people who tend to engage in certain kinds of reflection score high on both PD dilemma parameters; further research could examine how model-free vs model-based accounts of decision can incorporate this insight.

How to best interpret the difference between dilemma response patterns is the subject of ongoing investigation. For instance, future work might further clarify the content of reflection when people arrive at deontological decisions: it is possible people are reflecting on whether actions accord with universal moral norms, or could be justified as universal maxims, as suggested by classic deontological theory (Kant, 1797/1991). Yet, this finding may also involve reflecting on abstract moral rules (Körner \& Volk, 2014; Lammers \& Stapel, 2009), avoidance of violations in general (Gamez-Djokic \& Molden, 2017); concern for adhering to Divine 
Commands (Piazza \& Landy, 2013); adhering to religious values (McPhetres et al., 2018); strategically presenting oneself as warm, moral, and trustworthy (e.g., Rom \& Conway, 2018; Everett, Ingbretsen, Cushman, \& Cikara, 2017; Bostyn \& Roets, 2018), or perhaps a mixture of any and all of the above.

Existing research suggests a few mechanisms of deontological dilemma judgments that involve reflection. First, reflection can promote a more abstract conception of the self (e.g., Liberman, Sagristano, \& Trope, 2002), and abstract mindsets can promote deontological judgments in conditions when reflection is not inhibited (Körner \& Volk, 2014; Lammers \& Stapel, 2009). Second, religious reflection in particular might promote or select for abstract, deontological moral reasoning (McPhetres et al., 2018). For instance, divine command theory forbids harming others, thereby aligning with the deontological dilemma response (Piazza \& Landy, 2013) and religious values help guide dilemma decisions (Piazza \& Sousa, 2014; Szekely, Opre \& Miu, 2015). Relatedly, religious individuals tend to incorporate religion into their self-concept (Ysseldyk, Matheson, \& Anisman, 2010). So if reflection can promote a more abstract conception of the self (e.g., Liberman, Sagristano, \& Trope, 2002) and if an abstract mindset is associated with deontological judgments in conditions when reflection is not inhibited (e.g., Körner \& Volk, 2014), then more reflective religious individuals will reason more abstractly and thereby find themselves preferring more deontological judgments (Piazza \& Landy, 2013; Piazza \& Sousa, 2014; Reynolds \& Conway 2018). Of course, each of these mechanisms may operate independently of the others.

Note that none of these findings rules out the possibility that other non-reflective processes also independently contribute to deontological decisions, such as heuristic adherence to moral rules (Sunstein, 2005; Nichols \& Mallon, 2006), or affective reactions to causing or 
witnessing harm (e.g., Miller et al., 2014; Reynolds \& Conway, 2018; Szekely, Opre \& Miu, 2015). Hence, theorists should avoid simplistically associating reflection with only utilitarian judgments, and non-reflective processing with only deontological judgments, as clearly there is more complexity than previously appreciated. That said, these findings align with a great deal of work suggesting the basic dual process claim that cognitive processes play a relatively greater role in driving utilitarian than deontological judgments (e.g., Conway et al., 2018a).

One might think that these findings challenge the standard dual-process model of deontological dilemma judgments. After all, the standard dual-process model proposes that deontological dilemma judgments are primarily driven by emotional responses and involve reflection only to rationalize these emotional responses (Greene, 2008). Whereas our findings confirm that deontological dilemma judgments are compatible with certain types of reflective reasoning, our findings do not rule out that emotional responses also contribute to deontological responding. Surprisingly, empathic concern failed to correlate with deontological inclinations in the present studies, which may appear to undermine the argument for a contribution of emotion. However, we interpret this null effect with extreme caution, as it contrasts with the vast majority of findings on this topic (e.g., Conway et al., 2018a; Conway \& Gawronksi, 2013; Reynolds \& Conway, 2018; Szekely, Opre \& Miu, 2015).

Methodological implications. Conventional sacrificial dilemmas can be less sensitive than process dissociation dilemmas and related analyses. Conventional sacrificial dilemma analyses suggest that harm acceptance sometimes correlates with AOT (Baron et al., 2015) and CRT (Paxton, Ungar, \& Greene, 2012; Baron et al., 2015; Byrd 2019; Cova et al., 2018). Yet, dissociating deontological and utilitarian tendencies from other non-deontological and nonutilitarian tendencies via PD has clarified these results in two ways. First, PD has revealed that 
both deontological and utilitarian tendencies correlate with AOT. Second, PD has revealed that AOT and logical reflection mediated the correlation between dilemma judgments and arithmetic measures of reflection like CRTs. These findings suggest that actively open-minded thinking may be another measure whose suppressed correlation with harm acceptance on conventional sacrificial dilemmas can be clarified through PD (see Conway et al., 2018a, 2018b; Hayakawa, Tannenbaum, Costa, Corey, \& Keysar, 2017; Miller, Hannikainen, \& Cushman 2014; Muda, Niszczota, Białek, \& Conway, 2018; Reynolds \& Conway, 2018). Hence, researchers should exert caution when employing analyses that assume that correlates of one horn of sacrificial dilemmas must be anti-correlates or non-correlates of the other horn of the dilemmas. PD repeatedly shows that what correlates positively with one horn of a sacrificial dilemma sometimes correlates positively with the other horn as well.

The use of PD enables researchers to distinguish between people who accept causing harm with the goal of maximizing outcomes from people who simply accept causing harm regardless of outcomes - a tendency that is inconsistent with both deontological and utilitarian ethics. For example, psychopathy correlates positively with harm acceptance judgments in conventional sacrificial dilemmas (e.g., Bartels \& Pizarro, 2011), similar to performance on the CRT. However, PD reveals different underlying interpretations for these apparently parallel effects: greater psychopathy predicts accepting harm indiscriminately (e.g., Reynolds \& Conway, 2019), whereas greater reflection predicts accepting harm only if it maximizes outcomes. Moreover, unlike conventional analyses of sacrificial dilemmas that assess only how factors influence the relative strength of response tendencies, PD can reveal cases where a factor predicts increases in both response tendencies simultaneously - a pattern that cancels out for conventional dilemmas, which pit these response tendencies against one another. In this manner, 
PD revealed that open-minded and logical reflection predicted both utilitarian and deontological response patterns, suggesting that more open-minded and reflective people are more averse to causing harm indiscriminately.

It is important to note that the innovation of PD goes beyond its addition of congruent dilemmas to conventional incongruent dilemmas. PD provides more information than merely examining the raw correlations between each dilemma type and third variables because the PD parameters track variance in the pattern of responding across both types of scenarios. Hence, the U parameter tracks individual differences in both accepting harm on incongruent dilemmas and rejecting harm on congruent dilemmas (Figure 1), which is more informative than individual differences to each kind of dilemma in isolation.

Implications for philosophy. Historians of philosophy might not be surprised that some measures of reflection correlated with deontological inclinations. Indeed, famous conceptions of deontology describe such judgments as arising from reflection about the logical implications of universal moral norms (e.g., Kant, 1797/1991). Early dilemma research highlighted the intriguing inconsistency between the rational cognitive deliberation professed by deontological philosophers and the apparent absence of such deliberation lay deontological judgments (e.g., Greene et al., 2004). The current work suggests that this inconsistency may have been overstated - clearly reflection can contribute to deontological dilemma decision-making even if utilitarian responses may be more influenced by arithmetic reflection than deontological responses. After all, practicing philosophers tend to score particularly high on measures of reflective processing (Livengood, Sytsma, Feltz, Scheines, \& Machery, 2010; Byrd, 2019), and 
many philosophers endorse both deontological metaethics and deontological dilemma judgments (e.g., Conway et al., 2018a). ${ }^{18}$

However, these data do not merely confirm historical precedent; they also bear on contemporary philosophy. With the rise of the dual process model, some theorists appealed to findings linking utilitarian judgments to reflection suggesting that utilitarian judgments may be normatively superior to deontological judgments - the idea being that the utilitarian approach overcomes biases introduced by less reflective, affective, or heuristic processes theorized to drive deontological judgments (e.g., Baron, 1994; Greene, 2015; Bazerman \& Greene, 2010; cf. Bennis et al., 2010). However, the present data undermine this normative argument for the utilitarian approach. They suggest that some deontological judgments arise from the kind of cognitive reflection that can overcome biases. Therefore, by the dual process theorists' own lights, the present findings suggest that the normative value of deontological considerations is higher than what some dual process theorists have argued (e.g., Bennis, et al., 2010). Granted, the current evidence suggest that mathematical reflection contributes to utilitarian judgments more than deontological judgments. Hence, the broad dual process claim that utilitarian judgments involve more reflection than deontological judgments could be partially correct. Either way, the current findings undermine existing normative claims about the deontological and utilitarian approaches based on differences in reflection and suggest that theorists should look elsewhere for evidence to supports such normative claims.

\section{Limitations}

\footnotetext{
${ }^{18}$ That said, some evidence employing conventional incongruent dilemmas suggests that more reflective philosophers tend to prefer utilitarian over deontological judgments in sacrificial dilemmas (Byrd, 2019).
} 
Like all dilemma research, this work suffers from the limitation that it examines responses to hypothetical scenarios, and therefore runs the risk that it may track somewhat different psychological processes than those of real-world decisions. Indeed, some work finds only null or weak correlations between hypothetical and real-world dilemma decisions (Bostyn, Sevenhant, \& Roets, 2018; cf. Plunkett \& Greene, 2019), though such studies examine only conventional sacrificial dilemma decisions, and hence may suffer from the same suppression problems as other work in the field. Moreover, decisions on moral dilemmas appear to track some real-world decisions (e.g., Dickinson \& Masclet, 2018). Moreover, though dilemmas may be somewhat artificial, they have proven useful at shedding light on a swath of related literatures from neuroscience to hormone studies to decisions about autonomous vehicles (e.g., Greene, 2014; Bonnefon, Shariff, \& Rahwan, 2016), and hence remain a worthy target of study despite this limitation.

Second, some theorists have argued that most sacrificial dilemma research is limited by a confound between action and decision: the deontological response pattern entails inaction, whereas the utilitarian response pattern often entails action (e.g., Gawronski \& Beer, 2017). Hence, these theorists developed a new model, similar to PD, but with three parameters, called the CNI model (Gawronski, Armstrong, Conway, Friesdorf, \& Hütter, 2017). This model estimates the focus on consequences, or the $\mathrm{C}$ parameter, analogous to the $\mathrm{U}$ parameter in the current work, and two more parameters theorized to be confounded in the current work: the N parameter tracking a tendency to consistently prioritize the wellbeing of a single individual over the wellbeing of a group, and the I parameter tracking a tendency to remain inactive in the face of moral problems. Given the similarity between the PD and CNI method, one might expect to find similar correlation patterns between each model's parameters and various measures of 
reflection. Yet, initial CNI work suggests that reflection may predict different correlations in the PD model than the CNI, perhaps lower I parameter scores (Gawronski et al., 2017). So the PD and CNI models may not be as similar as they seem at first glance. Further, while the CNI model's N parameter tracks consistency across both prescriptive and proscriptive moral norms, both deontological theorists (Alexander \& Moore, 2016; Kant, 1785/1959) and lay people (Janoff-Bulman et al., 2009) treat proscriptive and prescriptive norms differently. Many deontological philosophers think that proscriptive duties are perfect-e.g., we should never be stealing (e.g., Kant, 1785/1959). However, such deontologists admit that prescriptive duties are imperfect - e.g., generally, we should give to charity, but we need not always be giving to charity (ibid.). Further, this prescriptive-proscriptive asymmetry is rejected by utilitarian philosophers (e.g., Singer, 1972). So although we agree with the CNI model's claim that both moral norms and preferences for inaction play a role in dilemma responses, we and other theorists remain open to the idea that combining these two features according to the PD model may not confound our interpretation of dilemma response patterns, but rather accurately express their features (e.g., Baron, 1994; Cushman, Knobe, \& Sinnott-Armstrong, 2008). Thus, it is not obvious how arithmetic and logical reflection would predict the CNI parameters after all. Future work might profitably examine this possibility.

\section{Conclusion}

The present studies partially replicate, but also clarify the relationships between reflection and moral dilemma judgments: arithmetic reflection predicted utilitarian but not deontological response patterns, whereas logical reflection predicted both deontological and utilitarian response patterns, and these dual positive effects largely cancelled out in conventional sacrificial dilemma judgments that treat them as opposites. Moreover, actively open-minded thinking and 
belief bias performance mediated the impact of arithmetic reflection on both utilitarian and deontological and utilitarian tendencies. Thus, different kinds of reflection may contribute to dilemma judgments in different ways, but these relationships are more complex and nuanced than recognized in previous work. 


\section{References}

Ackerman, R. (2014). The diminishing criterion model for metacognitive regulation of time investment. Journal of Experimental Psychology. General, 143(3), 1349-1368. doi:10.1037/a0035098

Alexander, L., \& Moore, M. (2016). Deontological Ethics. In Stanford Encyclopedia of Philosophy. Retrieved from https://plato.stanford.edu/entries/ethicsdeontological/\#MakNoConConPurDeoRat

Armstrong, J., Friesdorf, R., \& Conway, P. (2018). Clarifying gender differences in moral dilemma judgments: The complementary roles of harm aversion and action aversion. Social Psychological and Personality Science. doi:1948550618755873.

Arutyunova, K. R., Alexandrov, Y. I., \& Hauser, M. D. (2016). Sociocultural Influences on Moral Judgments: East-West, Male-Female, and Young-Old. Frontiers in Psychology, 7. doi:10.3389/fpsyg.2016.01334

Bago, B., \& De Neys, W. (2018). The intuitive greater good: Testing the corrective dual process model of moral cognition. Journal of Experimental Psychology. General. doi:10.1037/xge0000533

Baron, J. (1994). Nonconsequentialist decisions. Behavioral and Brain Sciences, 17(1), 1-10. doi:10.1017/S0140525X0003301X

Baron, J., Gürçay, B., Moore, A. B., \& Starcke, K. (2012). Use of a Rasch model to predict response times to utilitarian moral dilemmas. Synthese, 189(1), 107117. doi:10.1007/s11229-012-0121-z 
Baron, J., Scott, S., Fincher, K., \& Metz, S. E. (2015). Why does the Cognitive Reflection Test (sometimes) predict utilitarian moral judgment (and other things)? Journal of Applied Research in Memory and Cognition, 4, 265-284. doi:10.1016/j.jarmac.2014.09.003

Baron, J. (1994). Nonconsequentialist decisions. Behavioral and Brain Sciences, 17, 1-10.

Baron, J. (1995). Myside bias in thinking about abortion. Thinking \& Reasoning, 1(3), 221-235. doi:10.1080/13546789508256909

Bartels, D. M. (2008). Principled moral sentiment and the flexibility of moral judgment and decision making. Cognition, 108(2), 381-417. doi:10.1016/j.cognition.2008.03.001

Bartels, D. M., \& Pizarro, D. A. (2011). The mismeasure of morals: Antisocial personality traits predict utilitarian responses to moral dilemmas. Cognition, 121, 154-161. doi:10.1016/j.cognition.2011.05.010

Bazerman, M. H., \& Greene, J. D. (2010). In Favor of Clear Thinking: Incorporating Moral Rules Into a Wise Cost-Benefit Analysis - Commentary on Bennis, Medin, \& Bartels (2010). Perspectives on Psychological Science, 5(2), 209-212. doi:10.1177/1745691610362362

Bennis, W. M., Medin, D. L., \& Bartels, D. M. (2010). The costs and benefits of calculation and moral rules. Perspectives on Psychological Science, 5, 187-202.

Białek, M., \& De Neys, W. (2016). Conflict detection during moral decision-making: evidence for deontic reasoners' utilitarian sensitivity. Journal of Cognitive Psychology, O(0), 1-9. doi:10.1080/20445911.2016.1156118

Białek, M., \& Pennycook, G. (2017). The cognitive reflection test is robust to multiple exposures. Behavior Research Methods, 1-7. doi:10.3758/s13428-017-0963-x 
Böckenholt, U. (2012). The Cognitive-Miser Response Model: Testing for Intuitive and Deliberate Reasoning. Psychometrika, 77(2), 388-399. doi:10.1007/s11336-012-9251-y

Bonnefon, J. F., Shariff, A., \& Rahwan, I. (2016). The social dilemma of autonomous vehicles. Science, 352(6293), 1573-1576.

Bostyn, D. H., Sevenhant, S., \& Roets, A. (2018). Of Mice, Men, and Trolleys: Hypothetical Judgment Versus Real-Life Behavior in Trolley-Style Moral Dilemmas. Psychological science, 0956797617752640.

Byrd, N. (2019). Great Minds Do Not Think Alike: Individual Differences In Philosophers and Non-Philosophers Philosophical Judgment. Manuscript in preparation.

Campitelli, G., \& Gerrans, P. (2014). Does the cognitive reflection test measure cognitive reflection? A mathematical modeling approach. Memory \& Cognition, 42(3), 434-447. doi:10.3758/s13421-013-0367-9

Campitelli, G., \& Labollita, M. (2010). Correlations of cognitive reflection with judgments and choices. Judgment and Decision Making, 5(3), 182-191.

Cokely, E. T., Galesic, M., Schulz, E., Ghazal, S., \& Garcia-Retamero, R. (2012). Measuring risk literacy: The Berlin Numeracy Test. Judgment and Decision Making, 7(1), 25.

Conway, P., \& Gawronski, B. (2013). Deontological and utilitarian inclinations in moral decision-making: A process dissociation approach. Journal of Personality and Social Psychology, 104, 216-235. doi:10.1037/a0031021

Conway, P., Goldstein-Greenwood, J., Polacek, D., and Greene, J. D. (2018a). Sacrificial utilitarian judgments do reflect concern for the greater good: Clarification via process dissociation and the judgments of philosophers. Cognition, 179, 241-265. doi:10.1016/j.cognition.2018.04.018 
Conway, P., Weiss, A., Burgmer, P., \& Mussweiler, T. (2018b). Distrusting your moral compass: The impact of distrust mindsets on moral dilemma processing and judgments. Social Cognition. 36, 345-380. doi:10.1521/soco.2018.36.3.345

Cova, F., Strickland, B., Abatista, A. G. F., Allard, A., Andow, J., Attie, M., ... Zhou, X. (2018). Estimating the Reproducibility of Experimental Philosophy. PsyArXiv Preprints. doi:10.17605/OSF.IO/SXDAH

Crockett, M. J. (2013). Models of morality. Trends in Cognitive Sciences, 17(8), 363366. doi:10.1016/j.tics.2013.06.005

Cushman, F. (2013). Action, outcome, and value a dual-system framework for morality. Personality and Social Psychology Review, 17, 273-292.

Cushman, F., Knobe, J., \& Sinnott-Armstrong, W. (2008). Moral appraisals affect doing/allowing judgments. Cognition, 108(1), 281-289. doi:10.1016/j.cognition.2008.02.005

Davis, M. H. (1980). Interpersonal reactivity index. Edwin Mellen Press.

Davis, M. H. (1983). Measuring individual differences in empathy: Evidence for a multidimensional approach. Journal of Personality and Social Psychology, 44, 113-126. doi:10.1037/0022-3514.44.1.113

Daw, N. D., Gershman, S. J., Seymour, B., Dayan, P., \& Dolan, R. J. (2011). Model-Based Influences on Humans' Choices and Striatal Prediction Errors. Neuron, 69(6), 12041215. doi:10.1016/j.neuron.2011.02.027

Dickinson, D. L., \& Masclet, D. (2018). Using Ethical Dilemmas to Predict Antisocial Choices with Real Payoff Consequences: An Experimental Study (No. 2018-06). Center for 
Research in Economics and Management (CREM), University of Rennes 1, University of Caen and CNRS.

Evans, J. S. B. T., Barston, J. L., \& Pollard, P. (1983). On the conflict between logic and belief in syllogistic reasoning. Memory \& Cognition, 11(3), 295-306. doi:10.3758/BF03196976

Everett, J. A. C., Ingbretsen, Z., Cushman, F., \& Cikara, M. (2017). Deliberation erodes cooperative behavior - Even towards competitive out-groups, even when using a control condition, and even when eliminating selection bias. Journal of Experimental Social Psychology, 73, 76-81. doi:10.1016/j.jesp.2017.06.014

Faul, F., Erdfelder, E., Lang, A.-G., \& Buchner, A. (2007). G*Power 3: A flexible statistical power analysis program for the social, behavioral, and biomedical sciences. Behavior Research Methods, 39(2), 175-191. doi:10.3758/BF03193146

Finucane, M. L., \& Gullion, C. M. (2010). Developing a tool for measuring the decision-making competence of older adults. Psychology and Aging, 25, 271-288. doi:10.1037/a0019106

Fleischmann, A., Lammers, J., Conway, P., \& Galinsky, A. D. (2017). Paradoxical Effects of Power on Moral Thinking: Why Power Both Increases and Decreases Deontological and Utilitarian Moral Decisions. Social Psychological and Personality Science, 10(1), 110120. https://doi.org/10.1177/1948550617744022

Foot, P. (1967). The Problem of Abortion and the Doctrine of Double Effect. Oxford Review, 5, $5-15$.

Foot, P. (1995). Moral dilemmas revisited. In W. Sinnott-Armstrong (Ed.), Modality, Morality and Belief: Essays in Honor of Ruth Barcan Marcus (pp. 117-128). Cambridge: Cambridge University Press. 
Frederick, S. (2005). Cognitive Reflection and Decision Making. Journal of Economic Perspectives, 19, 25-42. doi:10.1257/089533005775196732

Friesdorf, R., Conway, P., \& Gawronski, B. (2015). Gender differences in responses to moral dilemmas: A process dissociation analysis. Personality and Social Psychology Bulletin, 42, 696-713. doi:10.1177/0146167215575731

Fumagalli, M., Ferrucci, R., Mameli, F., Marceglia, S., Mrakic-Sposta, S., Zago, S., ... Priori, A. (2010). Gender-related differences in moral judgments. Cognitive Processing, 11(3), 219-226. doi:10.1007/s10339-009-0335-2

Gamez-Djokic, M., \& Molden, D. (2017). Beyond affective influences on deontological moral judgment: The role of motivations for prevention in the moral condemnation of harm. Personality and Social Psychology Bulletin, 42, 1522-1537.

Gawronski, B., \& Beer, J. S. (2017). What makes moral dilemma judgments "utilitarian" or "deontological"? Social Neuroscience, 12, 626-632.

Gawronski, B., Armstrong, J., Friesdorf, R., Conway, P., \& Hütter, M. (2015). Moral dilemma judgments: Disentangling deontological inclinations, utilitarian inclinations, and general action tendencies. In J. P. Forgas, P. A. M. Van Lange, \& L. Jussim (Eds.), Social psychology of morality. New York: Psychology Press.

Gawronski, G., Conway, P., Friesdorf, R., Armstrong, J., \& Hütter, M. (2017). Consequences, Norms, and Generalized Inaction in Moral Dilemmas: The CNI Model of Moral Decision-Making. Journal of Personality and Social Psychology. Early Online Access. Gleichgerrcht, E., \& Young, L. (2013). Low Levels of Empathic Concern Predict Utilitarian Moral Judgment. PLoS ONE, 8(4), e60418. doi:10.1371/journal.pone.0060418 
Greene, J. D. (2015). Beyond Point-and-Shoot Morality: Why Cognitive Science Matters for Ethics. Law and Ethics of Human Rights, 9(2), 141-172.

Greene, J. D. (2013). Moral Tribes: Emotion, Reason, and the Gap Between Us and Them. Penguin.

Greene, J. D. (2008). The secret joke of Kant's soul. In W. Sinnott-Armstrong (Ed.), Moral Psychology: The Neuroscience of Morality: Emotion, Brain Disorders, and Development (Vol. 3, pp. 35-79). London: MIT Press.

Greene, J. D. (2007). Why are VMPFC patients more utilitarian? A dual-process theory of moral judgment explains. Trends in Cognitive Sciences, 11(8), 322-323.

Greene, J. D., Morelli, S. A., Lowenberg, K., Nystrom, L. E., \& Cohen, J. D. (2008). Cognitive load selectively interferes with utilitarian moral judgment. Cognition, 107, 1144-1154. doi:10.1016/j.cognition.2007.11.004

Greene, J. D., Nystrom, L. E., Engell, A. D., Darley, J. M., \& Cohen, J. D. (2004). The neural bases of cognitive conflict and control in moral judgment. Neuron, 44, 389-400.

Greene, J. D., Sommerville, R. B., Nystrom, L. E., Darley, J. M., \& Cohen, J. D. (2001). An fMRI investigation of emotional engagement in moral judgment. Science, 293, 21052108.

Haigh, M. (2016). Has the standard cognitive reflection test become a victim of its own success? Advances in cognitive psychology, 12, 145.

Hannikainen, I., \& Cova, F. (2019). Trait reflectivity and consequentialist ethics: A psychometric meta-analysis. Manuscript in preparation. 
Haran, U., Ritov, I., \& Mellers, B. A. (2013). The role of actively open-minded thinking in information acquisition, accuracy, and calibration. Judgment and Decision Making, 8, 188.

Hayakawa, S., Tannenbaum, D., Costa, A., Corey, J. D., \& Keysar, B. (2017). Thinking more or feeling less? Explaining the foreign-language effect on moral judgment. Psychological science, $28,1387-1397$.

Hayes, A. F., Montoya, A. K., \& Rockwood, N. J. (2017). The analysis of mechanisms and their contingencies: PROCESS versus structural equation modeling. Australasian Marketing Journal, 25, 76-81.

IBM Corp. Released 2013. IBM SPSS Statistics for Windows, Version 22.0. Armonk, NY: IBM Corp.

Jacoby, L. L. (1991). A process dissociation framework: Separating automatic from intentional uses of memory. Journal of Memory and Language, 30, 513-541.

Janis, I. L., \& Frick, F. (1943). The relationship between attitudes toward conclusions and errors in judging logical validity of syllogisms. Journal of Experimental Psychology, 33(1), 7377. doi:10.1037/h0060675

Janoff-Bulman, R., Sheikh, S., \& Hepp, S. (2009). Proscriptive versus prescriptive morality: Two faces of moral regulation. Journal of Personality and Social Psychology, 96, 521.

Johnson, C. M. (2019a). How Deontologists Can Be Moderate (and Why They Should Be). The Journal of Value Inquiry. Doi:10.1007/s10790-019-09692-7

_ (2019b). The Intrapersonal Paradox of Deontology. Journal of Moral Philosophy. Doi:10.1163/17455243-20182527 
Johnson-Laird, P., \& Bara, B. G. (1984). Syllogistic inference. Cognition, 16, 1-61. doi:10.1016/0010-0277(84)90035-0

Kahane, G., Everett, J. A. C., Earp, B. D., Farias, M., \& Savulescu, J. (2015). 'Utilitarian’ judgments in sacrificial moral dilemmas do not reflect impartial concern for the greater good. Cognition, 134, 193-209. doi:10.1016/j.cognition.2014.10.005

Kahane, G., Everett, J. A., Earp, B. D., Caviola, L., Faber, N. S., Crockett, M. J., \& Savulescu, J. (2018). Beyond Sacrificial Harm: A Two-Dimensional Model of Utilitarian Psychology. Psychological Review. Advance online publication. doi:10.1037/rev0000093

Kant, I. (1785/1959). Foundation of the Metaphysics of Morals (L. W. Beck, Trans.). Indianapolis: Bobbs-Merrill.

Kant, I. (1797/1991). The Metaphysics of Morals. (M. Gregor, Trans.) (1st edition). Cambridge ; New York: Cambridge University Press.

Kool, W., Cushman, F. A., \& Gershman, S. J. (2016). When Does Model-Based Control Pay Off? PLOS Computational Biology, 12(8), e1005090. doi:10.1371/journal.pcbi.1005090

Klauer, K. C., Dittrich, K., Scholtes, C., \& Voss, A. (2015). The invariance assumption in process-dissociation models: an evaluation across three domains. Journal of Experimental Psychology. General, 144(1), 198-221. Doi:10.1037/xge0000044

Kleber, J., Dickert, S., Peters, E., \& Florack, A. (2013). Same numbers, different meanings: How numeracy influences the importance of numbers for pro-social behavior. Journal of Experimental Social Psychology, 49(4), 699-705. doi:10.1016/j.jesp.2013.02.009

Krizo, P. (2012). A summer high school computer game programming curriculum and an assessment of its effects on student motivation (Master's Thesis, California State University, Sacramento). Retrieved from http://hdl.handle.net/10211.9/1481 
Koenigs, M., Young, L., Adolphs, R., Tranel, D., Cushman, F., Hauser, M., \& Damasio, A. (2007). Damage to the prefrontal cortex increases utilitarian moral judgments. Nature, 446, 908-911. doi:10.1038/nature05631

Körner, A., \& Volk, S. (2014). Concrete and abstract ways to deontology: Cognitive capacity moderates construal level effects on moral judgments. Journal of Experimental Social Psychology, 55, 139-145.

Koop, G. J. (2013). An assessment of the temporal dynamics of moral decisions. Judgment and Decision Making, 8, 527-539.

Lammers, J., \& Stapel, D. A. (2009). How power influences moral thinking. Journal of Personality and Social Psychology, 97(2), 279-289. doi:10.1037/a0015437

Lee, J. J., \& Gino, F. (2015). Poker-faced morality: Concealing emotions leads to utilitarian decision making. Organizational Behavior and Human Decision Processes, 126, 4964. doi:10.1016/j.obhdp.2014.10.006

Liberali, J. M., Reyna, V. F., Furlan, S., Stein, L. M., \& Pardo, S. T. (2012). Individual Differences in Numeracy and Cognitive Reflection, with Implications for Biases and Fallacies in Probability Judgment. Journal of Behavioral Decision Making, 25(4), 361381. doi:10.1002/bdm.752

Liberman, N., Sagristano, M. D., \& Trope, Y. (2002). The effect of temporal distance on level of mental construal. Journal of Experimental Social Psychology, 38(6), 523-534. doi:10.1016/S0022-1031(02)00535-8

Livengood, J., Sytsma, J., Feltz, A., Scheines, R., \& Machery, E. (2010). Philosophical temperament. Philosophical Psychology, 23(3), 313-330.

doi:10.1080/09515089.2010.490941 
Maranges, H., Reynolds, T., Conway, P. \& Baumeister, R. (2018). Self-Control as the Moral Dilemma Muscle: Trait Self-Control Predicts Both Deontological and Utilitarian Response Tendencies. Manuscript under review.

Markovits, H., \& Nantel, G. (1989). The belief-bias effect in the production and evaluation of logical conclusions. Memory \& Cognition, 17, 11-17. doi:10.3758/BF03199552

Miller, R. M., Hannikainen, I. A., \& Cushman, F. A. (2014). Bad Actions or Bad Outcomes? Differentiating affective contributions to the moral condemnation of harm. Emotion. Advance online publication. Emotion, 14(3), 573-587. doi:10.1037/a0035361

Schtulman, A., \& McCallum, K. (2014). Cognitive Reflection Predicts Science Understanding. In Proceedings of the Annual Meeting of the Cognitive Science Society.

McPhetres, J., Conway, P., Hughes, J., \& Zuckerman, M. (2018). reflecting on god's will: reflective processing contributes to religious peoples' deontological dilemma responses. Journal of Experimental Social Psychology, 79, 301-314. doi:10.1016/j.jesp.2018.08.013

Meyer, A., Zhou, E., \& Frederick, S. (2018). The non-effects of repeated exposure to the Cognitive Reflection Test. Judgment and Decision Making, 13(3), 246-259.

Mill, J. S. (1861/1998). Utilitarianism. In R. Crisp (Ed.), New York: Oxford University Press. Miller, R. M., Hannikainen, I. A., \& Cushman, F. A. (2014). Bad actions or bad outcomes? Differentiating affective contributions to the moral condemnation of harm. Emotion, 14, 573.

Moore, A. B., Clark, B. A., \& Kane, M. J. (2008). Who shalt not kill? Individual differences in working memory capacity, executive control, and moral judgment. Psychological Science, 19, 549-57. doi:10.1111/j.1467-9280.2008.02122.x 
Muda, R., Niszczota, P., Białek, M., \& Conway, P. (2018). Reading dilemmas in a foreign language reduces both deontological and utilitarian response tendencies. Journal of Experimental Psychology: Learning, Memory, \& Cognition, 44, 321-326. doi:10.1037/xlm0000447

Nichols, S., Mallon, R. (2006). Moral dilemmas and moral rules. Cognition, 100, 530-542. doi:10.1016/j.cognition.2005.07.005

Norcross, A. (2006). The scalar approach to utilitarianism. The Blackwell Guide to Mill's Utilitarianism, 217-232.

Oakhill, J. V., \& Johnson-Laird, P. N. (1985). The effects of belief on the spontaneous production of syllogistic conclusions. The Quarterly Journal of Experimental Psychology Section A, 37(4), 553-569. doi:10.1080/14640748508400919

Oldrati, V., Patricelli, J., Colombo, B., \& Antonietti, A. (2016). The role of dorsolateral prefrontal cortex in inhibition mechanism: A study on cognitive reflection test and similar tasks through neuromodulation. Neuropsychologia, 91, 499-508. doi:10.1016/j.neuropsychologia.2016.09.010

Oppenheimer, D. M., Meyvis, T., \& Davidenko, N. (2009). Instructional manipulation checks: Detecting satisficing to increase statistical power. Journal of Experimental Social Psychology, 45, 867-872.

Park, G., Kappes, A., Rho, Y., Van Bavel, J. (2016). At the heart of morality lies neuro-visceral integration: lower cardiac vagal tone predicts utilitarian moral judgment. Social Cognitive and Affective Neuroscience, 11(10), 1588-1596. doi:10.1093/scan/nsw077

Patel, N. (2017). The Cognitive Reflection Test: a measure of intuition/reflection, numeracy, and insight problem solving, and the implications for understanding real-world judgments 
and beliefs (Thesis). University of Missouri--Columbia. Retrieved from https://mospace.umsystem.edu/xmlui/handle/10355/62365

Patil, I., \& Silani, G. (2014). Reduced empathic concern leads to utilitarian moral judgments in trait alexithymia. Frontiers in Psychology, 5, 501. doi:10.3389/fpsyg.2014.00501

Patil, I., Zucchelli, M. M., Kool, W., Campbell, S., Fornasier, F., Calò, M., ... Cushman, F. A. (2019). Reasoning supports utilitarian resolutions to moral dilemmas across diverse measures. Early online archived version. doi:10.31234/osf.io/q86vx

Paxton, J. M., Ungar, L., \& Greene, J. D. (2012). Reflection and reasoning in moral judgment. Cognitive Science, 36, 163-177.

Paxton, J. M., Bruni, T., \& Greene, J. D. (2014). Are 'counter-intuitive' deontological judgments really counter-intuitive? An empirical reply to. Social Cognitive and Affective Neuroscience, 9(9), 1368-1371. doi:10.1093/scan/nst102

Payne, B. K., \& Bishara, A. J. (2009). An integrative review of process dissociation and related models in social cognition. European Review of Social Psychology, 20, 272-314. doi:10.1080/10463280903162177

Pennycook, G., Cheyne, J. A., Barr, N., Koehler, D. J., \& Fugelsang, J. A. (2014a). The role of analytic thinking in moral judgements and values. Thinking \& Reasoning, 20, 188-214.

Pennycook, G., Fugelsang, J. A., \& Koehler, D. J. (2015). What makes us think? A three-stage dual-process model of analytic engagement. Cognitive Psychology, 80, 3472. doi:10.1016/j.cogpsych.2015.05.001

Piazza, J., \& Landy, J. F. (2013). "Lean not on your own understanding": Belief that morality is founded on divine authority and non-utilitarian moral judgments. Judgment and Decision Making, 8(6), 639-661. 
Piazza, J., \& Sousa, P. (2014). Religiosity, Political Orientation, and Consequentialist Moral Thinking. Social Psychological and Personality Science, 5(3), 334-342. doi:10.1177/1948550613492826

Plunkett, D., \& Greene, J. D. (2019). Overlooked Evidence and a Misunderstanding of What Trolley Dilemmas Do Best: A Comment on Bostyn, Sevenhant, \& Roets (2018). Psychological Science.

Preacher, K. J., \& Hayes, A. F. (2004). SPSS and SAS procedures for estimating indirect effects in simple mediation models. Behavior Research Methods, Instruments, \& Computers, 36, $717-731$

Primi, C., Morsanyi, K., Chiesi, F., Donati, M. A., \& Hamilton, J. (2016). The Development and Testing of a New Version of the Cognitive Reflection Test Applying Item Response Theory (IRT). Journal of Behavioral Decision Making, 29(5), 453-469. doi:10.1002/bdm. 1883

Reyna, V. F., Nelson, W. L., Han, P. K., \& Dieckmann, N. F. (2009). How Numeracy Influences Risk Comprehension and Medical Decision Making. Psychological Bulletin, 135(6), 943-973.

Reynolds, C. J., Byrd, N., \& Conway, P. (2019). Trait reflectiveness and responses to moral dilemmas: A meta-analytic process dissociation approach. Manuscript in preparation.

Reynolds, C. J., \& Conway, P. (2018). Not just bad actions: Affective concern for bad outcomes contributes to moral condemnation of harm in moral dilemmas. Emotion.

Rom, S., \& Conway, P. (2018). The strategic moral self: Self-presentation shapes moral dilemma judgments. Journal of Experimental Social Psychology. 
Rom, S., Weiss, A., \& Conway, P. (2016). Judging those who judge: Perceivers infer the roles of affect and cognition underpinning others' moral dilemma responses. Journal of Experimental Social Psychology, 69, 44-58.

Ross, D. (1930/2003). The Right and the Good. (P. Stratton-Lake, Ed.) (2 edition). Oxford: Clarendon Press.

Royzman, E. B., Landy, J. F., \& Goodwin, G. P. (2014). Are good reasoners more incestfriendly? Trait cognitive reflection predicts selective moralization in a sample of American adults. Judgment and Decision Making, 9, 176-190.

Royzman, E. B., Landy, J. F., \& Leeman, R. F. (2014). Are thoughtful people more utilitarian? CRT as a unique predictor of moral minimalism in the dilemmatic context. Cognitive science, 39, 325-352. doi:10.1111/cogs.12136

Sidgwick, H. (1874). The Methods Of Ethics (7th ed.). Chicago: Hackett Publishing.

Singer, P. (1972). Famine, affluence, and morality. Philosophy \& Public Affairs, 229-243.

Sirota, M., \& Juanchich, M. (2018). Effect of response format on cognitive reflection: Validating a two- and four-option multiple choice question version of the Cognitive Reflection Test. Behavior Research Methods, 1-12. doi:10.3758/s13428-018-1029-4

Sirota, M., Kostovičová, L., Juanchich, M., Dewberry, C., \& Marshall, A. C. (2018). Measuring Cognitive Reflection without Maths: Developing and Validating the Verbal Cognitive Reflection Test. https://doi.org/10.31234/osf.io/pfe79

Stanovich, K. E., \& West, R. F. (1997). Reasoning independently of prior belief and individual differences in actively open-minded thinking. Journal of Educational Psychology, 89(2), 342. 
Stagnaro, M., Pennycook, G., \& Rand, D. G. (2018). Performance on the Cognitive Reflection Test is stable across time. Judgment and Decision Making, 13(3), 260-267.

Stieger, S., \& Reips, U. D. (2016). A limitation of the Cognitive Reflection Test: familiarity. PeerJ, 4, e2395.

Stupple, E. J. N., Ball, L. J., \& Ellis, D. (2013). Matching bias in logical reasoning: Evidence for a dual-process account from response times and confidence ratings. Thinking \& Reasoning, 19(1), 54-77. doi:10.1080/13546783.2012.735622

Stupple, E. J. N., Ball, L. J., Evans, J. S. B. T., \& Kamal-Smith, E. (2011). When logic and belief collide: Individual differences in reasoning times support a selective processing model. Journal of Cognitive Psychology, 23(8), 931941. doi:10.1080/20445911.2011.589381

Stupple, E. J. N., Pitchford, M., Ball, L. J., Hunt, T. E., \& Steel, R. (2017). Slower is not always better: Response-time evidence clarifies the limited role of miserly information processing in the Cognitive Reflection Test. PLOS ONE, 12(11), e0186404. doi:10.1371/journal.pone.0186404

Sunstein, C.R. (2005). Moral heuristics. Behavioral and Brain Sciences, 28, 531-573.

Szaszi, B., Szollosi, A., Palfi, B., \& Aczel, B. (2017). The cognitive reflection test revisited: exploring the ways individuals solve the test. Thinking \& Reasoning, O(0), 1-28. doi:10.1080/13546783.2017.1292954

Szekely, R. D., Opre, A., \& Miu, A. C. (2015). Religiosity enhances emotion and deontological choice in moral dilemmas. Personality and Individual Differences, 79, 104-109. doi:10.1016/j.paid.2015.01.036 
Thomson, J. J. (1986). Killing, letting die, and the trolley problem. In W. Parent (Ed.), Rights, Restitution, and Risk: Essays in Moral Theory. Harvard University Press.

Thomson, K. S., \& Oppenheimer, D. M. (2016). Investigating an alternate form of the cognitive reflection test. Judgment and Decision Making, 11(1), 99-113.

Toplak, M. E., \& Stanovich, K. E. (2002). The Domain Specificity and Generality of Disjunctive Reasoning: Searching for a Generalizable Critical Thinking Skill. Journal of Educational Psychology, 94(1), 197-209.

Toplak, M. E., West, R. F., \& Stanovich, K. E. (2011). The Cognitive Reflection Test as a predictor of performance on heuristics-and-biases tasks. Memory \& Cognition, 39, 1275.

Toplak, M. E., West, R. F., \& Stanovich, K. E. (2014). Assessing miserly information processing: An expansion of the Cognitive Reflection Test. Thinking \& Reasoning, 20(2), 147-168. doi:10.1080/13546783.2013.844729

Trémolière, B., Neys, W. D., \& Bonnefon, J.-F. (2012). Mortality salience and morality: Thinking about death makes people less utilitarian. Cognition, 124(3), 379-384. doi:10.1016/j.cognition.2012.05.011

Trémolière, B., De Neys, W., \& Bonnefon, J.-F. (2014). The grim reasoner: Analytical reasoning under mortality salience. Thinking \& Reasoning, 20(3), 333-351. doi:10.1080/13546783.2013.823888

Trémolière, B., \& Bonnefon, J.-F. (2014). Efficient kill-save ratios ease up the cognitive demands on counterintuitive moral utilitarianism. Personality and Social Psychology Bulletin, 40, 923-930.

Welsh, M. B., \& Begg, S. H. (2017). The Cognitive Reflection Test: familiarity and predictive power in professionals. Presented at the Annual Meeting of the Cognitive Science 
Society, London. Retrieved from https://pdfs.semanticscholar.org/dc22/102691e898cee5d2c9a110a3837190b70a0d.pdf

Wiech, K., Kahane, G., Shackel, N., Farias, M., Savulescu, J., \& Tracey, I. (2013). Cold or calculating? Reduced activity in the subgenual cingulate reflects decreased aversion to harming in counterintuitive utilitarian judgment. Cognition, 126, 364-372.

Ysseldyk, R., Matheson, K., \& Anisman, H. (2010). Religiosity as Identity: Toward an Understanding of Religion From a Social Identity Perspective. Personality and Social Psychology Review, 14(1), 60-71. doi:10.1177/1088868309349693 


\section{Appendix - Process Dissociation Calculations for Moral Dilemma Judgments}

Calculating the deontology and utilitarian PD parameters requires examining responses to both congruent and incongruent dilemmas. Utilitarianism entails maximizing overall outcomes, whereas deontology entails avoiding causing harm regardless of outcomes. Harmful action maximizes overall outcomes in the incongruent, but not congruent, dilemmas. Therefore, utilitarianism and deontology lead to different response patterns across dilemma variants. Consider the processing tree depicted in Figure 1: The top path illustrates the case where utilitarianism drives the response to a dilemma, which entails rejecting harm for congruent dilemmas but accepting harm for incongruent dilemmas. The second path illustrates the case where deontology drives the response to a dilemma, which entails rejecting harm for both congruent and incongruent dilemmas. Finally, the bottom path represents the case where neither utilitarianism nor deontology drives the response to a dilemma; this case entails accepting harm for both congruent and incongruent dilemmas.

Using the two columns on the right side of the figure, it is possible to work backward to determine which cases led participants to judge harm as acceptable or unacceptable for both congruent and incongruent dilemmas. For congruent dilemmas, harm is unacceptable when either utilitarianism drives the response, $U$, or when deontology drives the response, $(1-U) \times D$. Conversely, harm is acceptable on congruent dilemmas when neither utilitarianism nor deontology drives the response, $(1-U) \times(1-D)$. For incongruent dilemmas, harm is unacceptable when deontology drives the response, $(1-U) \times D$. Conversely, harm is acceptable either when utilitarianism drives the response, $U$, or when neither utilitarianism nor deontology drives the response, $(1-U) \times(1-D)$. 
By combining these cases, it becomes possible to algebraically represent the probability of a particular judgment. For example, the probability of judging harm as unacceptable for congruent dilemmas is represented by the case where either utilitarianism drives responses or deontology drives responses:

Eq. (A.1) $p$ (unacceptable $\mid$ congruent $)=U+[(1-\mathrm{U}) \times \mathrm{D}]$

Conversely, the probability of judging harm as acceptable in congruent dilemmas is represented by the case that neither utilitarianism nor deontology drives responses:

Eq. (A.2) $p($ acceptable $\mid$ congruent $)=(1-\mathrm{U}) \times(1-\mathrm{D})$

For incongruent dilemmas, the probability of judging harm as unacceptable is represented by the case that deontology drives responses:

Eq. (A.3) $p$ (unacceptable $\mid$ incongruent $)=(1-\mathrm{U}) \times \mathrm{D}$

Conversely, the probability of judging harm as acceptable for incongruent dilemmas is represented by the cases that utilitarianism drives responses, or neither deontology nor utilitarianism drives responses:

Eq. (A.4) $p$ (acceptable $\mid$ incongruent $)=U+[(1-\mathrm{U}) \times(1-\mathrm{D})]$

Once the probabilities of accepting and rejecting harm in congruent and incongruent dilemmas are represented algebraically, it becomes possible to enter a participants' pattern of actual responses across multiple congruent and incongruent dilemmas, and algebraically combine these equations in order to solve for two parameters estimating deontological $(D)$ and utilitarian $(U)$ inclinations underpinning their responses. In particular, by including Equation 3 into Equation 1, the latter can be solved for $U$, leading to the following formula:

Eq. (A.5) $\mathrm{U}=p$ (unacceptable $\mid$ congruent) $-p$ (unacceptable $\mid$ incongruent) 
Moreover, by including the calculated value for $U$ in Equation 3, this equation can be solved for $D$, leading to the following formula:

Eq. (A.6) $\mathrm{D}=p$ (unacceptable $\mid$ incongruent $) /(1-\mathrm{U})$

Together, these formulas enable researchers to obtain parameters that independently estimate the strength of deontological and utilitarian inclinations underlying conventional sacrificial moral dilemma judgments and dissociate these inclinations from other, nondeontological, and non-utilitarian inclinations.

This method could be called the 'U-first' method since it starts with the U parameter, making $U$ the "dominant process" and then derives the D parameter, making D the "nondominant process" (Klauer et al., 2015). However, dilemma response parameters can also be assessed with the reverse, 'D-first' method, by starting with the D parameter and then deriving the U parameter. Past work repeatedly found that both the U-first and D-first methods produce nearly identical results (e.g., Conway \& Gawronski, 2013; Appendix B; Conway et al., 2018b, Footnote 2). Hence, despite valid concerns about the invariance assumption of process dissociation in general (Klauer et al., 2015), various applications of process dissociation to moral dilemmas suggests that the invariance assumption turns out to be unproblematic for PD dilemma analysis. 


\section{Supplement A - Data Archiving}

All data files and SPSS analysis syntax are available from the Open Science Framework:

https://osf.io/y4mdw/ 


\section{Supplement B - Study 1, Factor Analysis}

The results of Study 1 suggested that the various measures of reflection employed by Baron and colleagues can be divided into at least two conceptually different types of reflection: arithmetic and logical, on the basis of the findings that these measures demonstrate quite different patterns in terms of predicting dilemma judgments. Yet, the question remains whether a factor analysis would reveal a similar distinction in terms of the variance of responses to these measures. Thus, we conducted an exploratory principle components analysis ${ }^{19}$ with oblimin rotation on all measures of reflection (i.e., all variants of the CRT, all variants of belief bias, other syllogism items, and verbal reasoning items, but we did not include measures of lured responses to avoid redundancy). This analysis revealed three factors with eigenvalues greater than $1(3.65,1.13$, and 1.04$)$ that together accounted for $72.65 \%$ of the variance (Table S1). Five items loaded above .4 on the first factor, which appeared to represent a combination of mathematical and logical reasoning: original belief bias, other logical reasoning, New CRT without Lure Performance, Original CRT performance, and New CRT with Lures Performance (see Table 2). Three items loaded above .4 on the second factor, most of which involve lures and mathematical reasoning: Original CRT performance, New CRT with Lure Performance, and other logical reasoning. Two items loaded above .4 on the third factor, both of which involve logical reasoning: no-lure belief bias and consistent belief bias. This suggests that some measures of reflection capture more arithmetic reflection while other measures of reflection capture more logical reflection, even though most items appear to share a common degree of variance (first factor) suggestive of some general component of reflection. This interpretation is largely

\footnotetext{
${ }^{19}$ A principle axis factor analysis produced very similar results.
} 
consistent with past factor analyses finding that arithmetic measures of reflection loaded different factors than logical measures of reflection (Baron et al. 2015, figure 3). 
Table S1. The pattern matrix derived from a principle components analysis with oblimin rotation revealed three factors with eigenvalues greater than 1, suggesting that factors corresponding to general reflection, avoidance of lured responses on mostly arithmetic items, and logical reflection, though not all factor loadings emerged as one would expect in Study 1.

\begin{tabular}{lccc}
\hline & \multicolumn{3}{c}{ Factor } \\
& 1 & 2 & 3 \\
\hline Original CRT, Correct Responses & .476 & -.678 & -.199 \\
New CRT, Correct Responses & .519 & -.572 & .095 \\
New No Lure CRT, Correct Responses & .642 & -.151 & .209 \\
Original Belief Bias & .794 & -.048 & -.038 \\
No-lure Belief Bias & .267 & .107 & .776 \\
Consistent Belief Bias & -.113 & -.118 & .904 \\
Other Syllogisms & .790 & -.048 & -.038 \\
Verbal Reasoning Items & -.191 & -.860 & -.117 \\
\hline
\end{tabular}

Note: Rotation converged in 10 iterations. 


\section{Supplement C - Study 2, Factor Analysis}

In order to see if arithmetic and logical reflection items loaded onto a single factor or onto different factors, we conducted an exploratory principle components analysis ${ }^{20}$ with oblimin rotation on all of the measures of reflection (i.e., all CRT measures, belief bias measures, syllogism, and verbal reasoning items, Berlin Numeracy test, and AOT, but no measures of lured responses). This analysis revealed two factors with eigenvalues greater than 1 (3.56 and 1.20) that together accounted for $59.50 \%$ of the variance. Six items loaded above .4 on the first factor, most of which involve arithmetic: numeracy, Original CRT performance, New CRT with Lures Performance, New CRT without Lure Performance, original belief bias, and verbal reasoning items (see Table S2). Four items loaded above .4 on the second factor, most of which involve syllogisms: AOT, no-lure belief bias, consistent belief bias, and other logical reasoning. This suggests that some measures of reflection capture more arithmetic reflection while other measures of reflection capture more logical reflection (although this was not a perfect distinction). Again, this interpretation is largely consistent with past factor analyses finding that arithmetic measures of reflection loaded a different factor than logical measures of reflection (Baron et al. 2015, figure 3).

\footnotetext{
${ }^{20}$ A principle axis factor analysis produced very similar results.
} 
Table S2. The pattern matrix derived from a principle components analysis with oblimin rotation revealed two factors with eigenvalues greater than 1, suggesting factors corresponding mostly to arithmetic reflection and mostly to logical reflection, though not all factor loadings emerged as one would expect in Study 2.

\begin{tabular}{lcc}
\hline & 1 & Factor \\
\hline Actively Open-Minded Thinking & .355 & .414 \\
Berlin Numeracy Test & .456 & .244 \\
Original CRT, Correct Responses & .876 & -.035 \\
New CRT, Correct Responses & .850 & .051 \\
New No Lure CRT, Correct Responses & .593 & .394 \\
Original Belief Bias & .531 & .379 \\
No-lure Belief Bias & .136 & .748 \\
Consistent Belief Bias & -.257 & .823 \\
Other Syllogisms & .223 & .535 \\
Verbal Reasoning Items & .552 & -.185 \\
\hline
\end{tabular}

Note: Rotation converged in 18 iterations. 